\title{
The Effects of Globalization on Macroeconomic Dynamics in a Trade-Dependent Economy: the Case of Korea*
}

\author{
Fabio MILANI \\ Department of Economics \\ University of California, Irvine
}

\author{
Sung Ho PARK \\ Economic Research Institute \\ Bank of Korea
}

\begin{abstract}
This paper studies the implications of globalization for the dynamics of macroeconomic variables over the business cycle for a small open trade-dependent economy, such as South Korea.

We study the impact of globalization through the lens of a structural model. Globalization is modeled as a time-varying degree of openness in the economy. We estimate the model allowing for non-fully rational expectations, learning by economic agents, and incomplete international financial markets.

The empirical results show that globalization led to important changes in the macroeconomic environment. Domestic variables have become much more sensitive toward global measures over the 1991-2012 sample. In particular, domestic output and inflation are significantly affected by global output. Fluctuations in Korean output, inflation, and interest rates, which were driven for the most part by domestic shocks in the early 1990s are, by the end of the sample, due in large part (roughly 70\%) to global shocks (and shocks that are open-economy in nature).
\end{abstract}

Keywords: Globalization, Inflation Dynamics, Global Slack Hypothesis, Inflation Expectations, Openness, Small Open Economy DSGE Model, Korea.

JEL classification: E31, E32, E50, E52, E58, F41, F62.

[The views expressed herein are those of authors and do not necessarily reflect the official views of the Bank of Korea. When reporting or citing this paper, the authors' name should always be explicitly stated.]

*We would like to thank seminar participants at the Bank of Korea for comments and discussions. Professor Milani acknowledges and is grateful for the financial support provided by the Bank of Korea regarding this research project. All remaining errors are our own. 


\section{Contents}

1 Introduction $\quad 1$

2 Small Open Economy Model 5

2.1 Model Description . . . . . . . . . . . . . . . . . . . . 5

2.1 .1 Households . . . . . . . . . . . . . . . . . . . 5

2.1 .2 Firms . . . . . . . . . . . . . . . . . . . 7

2.1.3 Exchange Rate, Terms of Trade, Monetary Policy . . . . . . . . . . . . . 8

2.2 Model Summary . . . . . . . . . . . . . . . . . . . . . . . . 9

2.3 Non-Fully Rational Expectations . . . . . . . . . . . . . . . . . . . . . 11

3 Estimation Details $\quad 12$

3.1 State Space . . . . . . . . . . . . . . . . . . . . . 12

3.2 Data . . . . . . . . . . . . . . . . . . . . . 12

3.3 Bayesian Approach . . . . . . . . . . . . . . . . 15

4 Results $\quad 16$

4.1 Structural Estimates . . . . . . . . . . . . . . . . . . . 16

4.2 Globalization and Macroeconomic Dynamics . . . . . . . . . . . . . 18

4.3 The Role of Domestic and Global Shocks . . . . . . . . . . . . . . . . . . 20

5 Robustness $\quad 24$

6 Conclusions $\quad 27$ 


\section{Introduction}

One of the most significant changes that affected the world economy over the last three decades has been the rapid increase in trade integration among economies around the globe. In terms of economic research, this process of globalization has spawned interest, in particular, in the fields of international trade and labor, with researchers predominantly focusing their attention on the role of globalization as the potential cause of the increase in wage inequality across skill levels in the U.S. and other countries. Research on the implications of globalization at the macroeconomic level, however, has somewhat lagged behind.

But globalization is also likely to produce a variety of effects on the macroeconomy. Various researchers (e.g., Rogoff (2003), Ball (2008), Taylor (2008), and so forth) and policy-makers (e.g., Fisher (2006), Bernanke (2007), Mishkin (2009), and so forth) have noticed and debated the potential impact of globalization on macroeconomic variables and monetary policy, as well as the challenges that it poses for state-of-the-art models. With regard to the dynamics of macro variables, these debates played a central role in the literature that defines the so-called Globalization Hypothesis (GH), or, alternatively, the 'Global Slack' Hypothesis, whose central claim is that global factors, in contrast to domestic factors, have become progressively more influential in determining domestic macroeconomic aggregates.

The existing empirical evidence on the effects of globalization at the macroeconomic level, however, is so far mixed at best. For example, Borio and Filardo (2007) find that domestic inflation rates, even in the U.S., have become more a function of global measures of economic activity, rather than of conventional domestic indicators. On the contrary, Ihrig et al. (2010) explore different specifications and conclude that global output does not have significant effects on domestic U.S. inflation: conventional closed-economy Phillips curves still are sufficient descriptions of the data. Milani (2012) shows that globalization has only a limited impact on macroeconomic relationships in the U.S., providing empirical evidence that corroborates the theoretical arguments made in Woodford (2007) and Gali (2011), who both exploit open-economy two-country settings to claim that it is very unlikely that U.S. inflation and monetary policy effectiveness may be affected by globalization in a quantitatively significant way. Overall, most of the empirical evidence is therefore consistent with a limited impact of globalization on macroeconomic relationships.

The focus on the U.S. is, however, not ideal if one is interested in assessing the changes that globalization may have induced in single economies. Although the trade component of GDP has progressively increased, the U.S. economy still remains quite closed.

In this paper, we take a different direction and choose to study the impact of globalization in 
a highly globally-integrated economy, instead. In this regard, Korea is an ideal example to assess whether globalization played any role in the behavior of macroeconomic aggregates. The country's economy heavily depends on international trade with the rest of the world and the role of trade has substantially increased over time, particularly so over the last two decades. Figure 1 shows the ratio of combined export and import to nominal GDP for five countries over the last two decades. The level of openness in Korea is two or three times higher than that in other countries. Also, the increase in the ratio in Korea is over $40 \%$, while the increase for other countries, with the exception of India, remains below $20 \%$.

Figure 1: Trade Openness (Ratio of combined Exports and Imports to Nominal GDP).

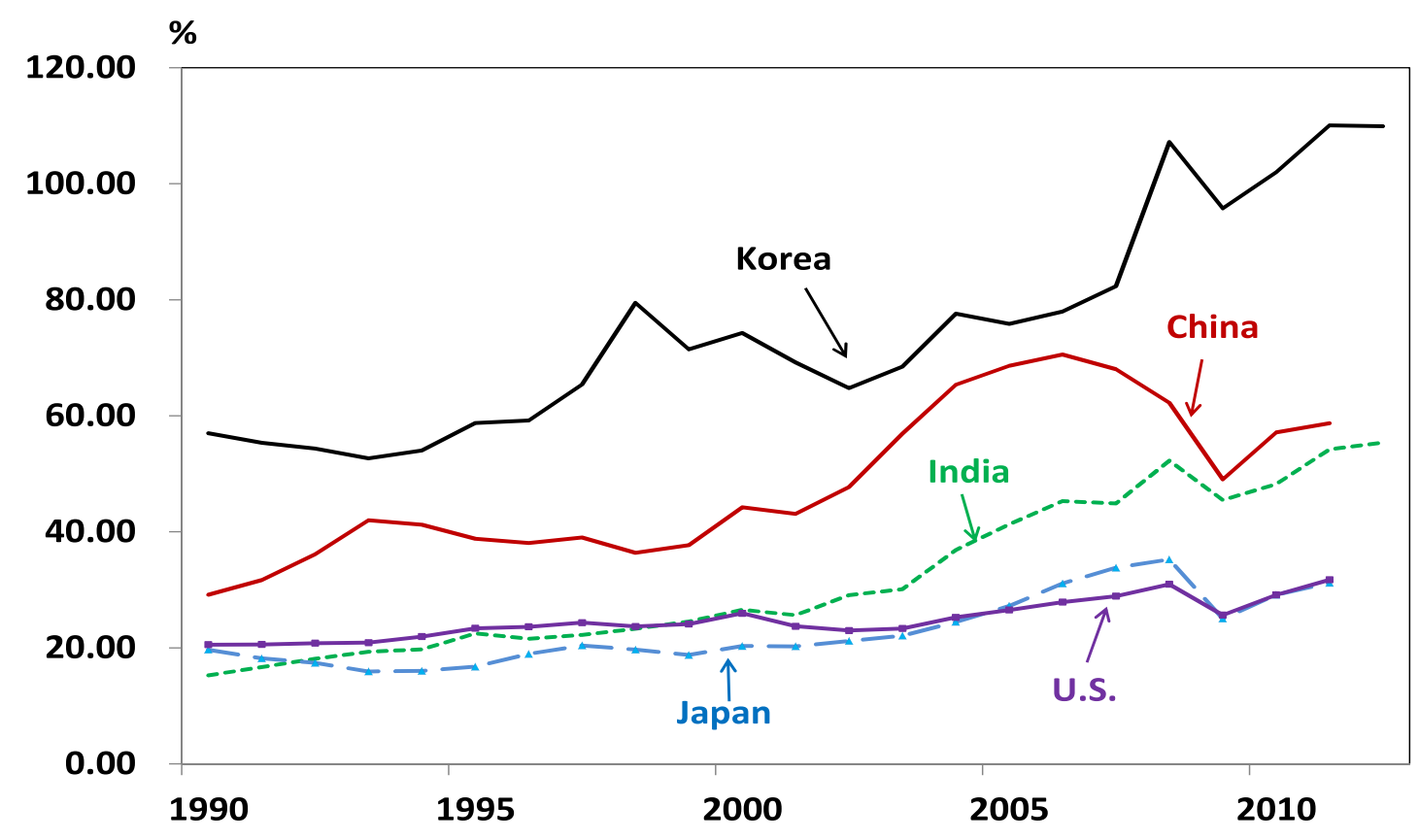

Source: World Development Indicator (World Bank).

Our analysis for Korea as an example of a small open economy subject to globalization aims to shed light on a number of questions:

- have domestic variables become more responsive to global, rather than domestic, measures of slack?

- has monetary policy become less effective because of globalization?

- what shares of macroeconomic fluctuations are due to external and global, rather than internal, factors? 
- have these shares changed over time as a result of globalization?

To answer those questions, we use a structural approach by exploiting and estimating a small open economy model, which includes several features that have been shown necessary in fitting aggregate time series data in both closed and open-economy frameworks, such as habit formation in consumption, sticky prices, indexation to past inflation, and so forth.

As a departure from conventional estimations, we relax the assumption of rational expectations, which is standard in open-economy macroeconomics. In a changing economy, the informational assumptions required by rational expectations would be exceedingly strong (i.e., agents would be required to optimize taking into account changes in future openness: this complicates the microfoundations and it doesn't seem realistic), more so than in typical constant-parameter environments. We instead model expectations as near-rational, and allow private-sector agents to learn over time the relevant economic relationships. In the spirit of the macroeconomic adaptive learning literature (e.g., Evans and Honkapohja (2001)), we constrain agents in the model to have no information advantage over the researchers and econometricians working with the model (i.e., if econometricians do not observe the shocks and the model parameters, neither do the agents in the model).

Moreover, given the plethora of evidence against the existence of financial market completeness at the international level, we assume incomplete international financial markets. Among other things, this assumption allows us to attenuate the restrictions imposed by the uncovered interest parity condition on exchange rate fluctuations, by allowing for a debt-elastic interest rate premium.

The structural small open economy model is estimated using full-information Bayesian methods. The coefficients in the state-space representation of the model are time-varying because they are a function of the degree of openness in the economy, which is itself time-varying and is the key channel exploited here to model globalization, and also because of economic agents' gradual learning about the economy.

Results Overview. The empirical results reveal the significant effects that globalization has had on business cycle dynamics in Korea. The relationships among the major domestic and foreign variables have fundamentally changed. Korean output has progressively become more sensitive to global output and less dependent on domestic consumption. Domestic inflation is also driven to a large extent by global, rather than exclusively domestic, slack. The influence of open-economy variables, such as the terms of trade and exchange rate or risk premium shocks, has risen over the sample. These developments are clearly exemplified by a variance decomposition exercise. While domestic shocks to preferences, technology, and monetary policy account for more than $70 \%$ of business cycle fluctuations at the beginning of the 1990s, the situation is reversed as it is external 
shocks (either global variables or variables related to open economy in nature such as the terms of trade or exchange rates) that come to dominate by the end of the sample. Those explain roughly $70 \%$ of the observed variability in output, inflation, and interest rates.

Related Literature. At the broadest level, this paper aims to contribute to our understanding of the changes in the structure and dynamics of economies that are brought by the process of globalization. While economists have focused a large deal of attention on globalization as a potential cause of the increase in wage inequality between high-skilled and low-skilled workers, research on its implications for business cycle dynamics has been less common. As discussed above, the papers that looked at the potential effects of globalization with a more macroeconomic focus emphasized how globalization could change the dynamics of inflation, by making it more a function of global, rather than domestic, measures. This paper contributes to this line of research by providing evidence from a country that has been potentially more sensitive to the forces of globalization.

On a methodological level, the paper presents an estimation of a microfounded small open economy model, which departs from conventional estimations in the literature in two main respects: first, it incorporates globalization, modeled in a highly tractable way, as a time-varying structural parameter; and second, it departs from the assumption of rational expectations, which can be unrealistically strong for economies that have moved from emerging to developed, and have been subject to major structural changes over the period. As the estimation recognizes the difficulties economic agents face in forming expectations in real time, it models expectations as non-fully rational (although still close to rational), but also allows agents to progressively learn about the economy.

At a more specific level, the paper provides an empirical investigation of the Korean economy, which reveals major changes in its characteristics over time. There are several studies that address how the Korean economy is affected by external shocks or foreign factors. These papers generally show that the business cycle in Korea is influenced by external shocks, although domestic monetary policy still remains effective. For example, Kim and Park (2009) and Kim (2011) use SVAR and find that output and inflation rate in Korea are affected by external shocks. Kang and Mook (2009) claim, based on the results from Factor-Augmented VARs, that monetary policy in Korea is still effective even though domestic economic variables are unilaterally affected by foreign factors. These studies, however, neither show how the effects of foreign factors on business cycles in Korea change over time, nor explicitly deal with globalization. 


\section{Small Open Economy Model}

The model is based on the small-open economy environments developed in Monacelli (2005), and Galí and Monacelli (2005). The version used in the paper mirrors the model with incomplete markets and endogenous sources of persistence, which is estimated in Justiniano and Preston (2010a). ${ }^{1}$ We only present a sketch of the main features of the model here. The reader is referred to the original papers for a detailed derivation.

\subsection{Model Description}

\subsubsection{Households}

Households derive utility from their total consumption $C_{t}$, in deviation from a stock of consumption habits that they have accumulated up to that period, and they suffer disutility from hours of labor supplied $N_{t}$. They are assumed to maximize

$$
E_{0} \sum_{t=0}^{\infty} \beta^{t} \tilde{\zeta}_{t}\left[\frac{\left(C_{t}-h C_{t-1}\right)^{1-\sigma}}{1-\sigma}-\frac{N_{t}^{1+\varphi}}{1+\varphi}\right]
$$

The parameters $0 \leq \beta \leq 1,0 \leq h \leq 1, \sigma>0$, and $\varphi>0$, denote the household's discount factor, the degree of (external) habit formation in consumption, and the inverse of the elasticities of intertemporal substitution in consumption and of labor supply. The term $\tilde{\zeta}_{t}$ represents an exogenous aggregate preference (or taste) shock, which can be interpreted, for example, as a disturbance to the degree of consumers' impatience.

The aggregate consumption term that enters households' utility function is a composite index of the Dixit-Stiglitz aggregates, $C_{H, t}$ and $C_{F, t}$, of domestically and foreign-produced goods:

$$
C_{t}=\left[(1-\alpha)^{1 / \eta} C_{H, t}^{\frac{\eta-1}{\eta}}+\alpha^{1 / \eta} C_{F, t}^{\frac{\eta-1}{\eta}}\right]^{\frac{\eta}{\eta-1}},
$$

where $0 \leq \alpha \leq 1$ denotes the share of foreign goods in the consumption basket and is typically interpreted as the degree of openness of the domestic economy, and where $\eta>0$ denotes the elasticity of substitution across domestic and foreign goods. The aggregate indexes $C_{H, t}$ and $C_{F, t}$ are given by

$$
\begin{aligned}
C_{H, t} & =\left[\int_{0}^{1} C_{H, t}(j)^{\frac{\varepsilon-1}{\varepsilon}} d j\right]^{\frac{\varepsilon}{\varepsilon-1}}, \\
C_{F, t} & =\left[\int_{0}^{1} C_{F, t}(j)^{\frac{\varepsilon-1}{\varepsilon}} d j\right]^{\frac{\varepsilon}{\varepsilon-1}},
\end{aligned}
$$

\footnotetext{
${ }^{1}$ Similar models, under rational expectations and constant openness, have been estimated in Kam et al. (2009), Justiniano and Preston (2010b), and Beltran and Draper (2008), among several others.
} 
where $\varepsilon>1$ indicates the elasticity of substitution across differentiated goods, produced either domestically or abroad.

Households maximize Equation (1) subject to a budget constraint, which is given in any period by

$$
P_{t} C_{t}+B_{t}+\Xi_{t} B_{t}^{*}=\left(1+i_{t-1}\right) B_{t-1}+\left(1+i_{t-1}^{*}\right) \phi_{t}\left(A_{t}\right) \Xi_{t} B_{t-1}^{*}+W_{t} N_{t}+\Pi_{H, t}+\Pi_{F, t}+T_{t},
$$

where $P_{t}$ denotes the aggregate price level, $B_{t}$ holdings of domestic (one-period) bonds, $B_{t}^{*}$ holdings of foreign (one-period) bonds, $W_{t}$ the nominal wage, $\Pi_{H, t}$ and $\Pi_{F, t}$ profits distributions obtained from the ownership of domestic and foreign firms, and $T_{t}$ lump-sum taxes or transfers. International financial markets are incomplete, since investors have access only to domestic and foreign one-period bonds, rather than to the full set of Arrow-Debreu securities. Domestic bonds yield the interest rate $i_{t}$, while foreign bonds yield the interest rate $i_{t}^{*}$ and their rate of return also depends on the (nominal) exchange rate $\Xi_{t}$ and on the interest-rate (risk) premium $\phi_{t}\left(A_{t}\right)$, which is assumed to be a positive function of the country's level of foreign debt as a fraction of steady-state output $\bar{Y}$, and is modeled as

$$
\begin{aligned}
\phi_{t} & =\exp \left[-\chi\left(A_{t}+\tilde{\phi}_{t}\right)\right] \\
A_{t} & \equiv \frac{\Xi_{t-1} B_{t-1}^{*}}{\bar{Y} P_{t-1}}
\end{aligned}
$$

where $\tilde{\phi}_{t}$ denotes the exogenous component of the risk-premium. Households allocate consumption expenditures for each differentiated consumption good $j$, and across domestic and foreign goods, according to the demand functions as below

$$
\begin{aligned}
C_{H, t}(j) & =\left(P_{H, t}(j) / P_{H, t}\right)^{-\varepsilon} C_{H, t}, \\
C_{F, t}(j) & =\left(P_{F, t}(j) / P_{F, t}\right)^{-\varepsilon} C_{F, t}, \\
C_{H, t} & =(1-\alpha)\left(P_{H, t} / P_{t}\right)^{-\eta} C_{t}, \\
C_{F, t} & =\alpha\left(P_{F, t} / P_{t}\right)^{-\eta} C_{t},
\end{aligned}
$$

where $P_{H, t}$ and $P_{F, t}$ denote aggregate price indexes corresponding to domestic and foreign consumption baskets, and $P_{t}=\left[(1-\alpha) P_{H, t}^{1-\eta}+\alpha P_{F, t}^{1-\eta}\right]^{1 /(1-\eta)}$ is the consumer price index (CPI). The elasticity across differentiated goods $\varepsilon$ is allowed to differ from the elasticity between domestic and foreign goods $\eta$.

The intratemporal and intertemporal optimality conditions are given by the following: 


$$
\begin{aligned}
\lambda_{t} & =\tilde{\zeta}_{t}\left(C_{t}-h C_{t-1}\right)^{-\sigma^{-1}}, \\
\lambda_{t} & =\tilde{\zeta}_{t} P_{t} N_{t}^{\varphi} / W_{t}, \\
\lambda_{t} & =E_{t}\left[\beta\left(1+i_{t}^{*}\right) \phi_{t+1} \lambda_{t+1} \frac{\Xi_{t+1}}{\Xi_{t}} \Pi_{t}\right], \\
\lambda_{t} & =E_{t}\left[\beta\left(1+i_{t}\right) \lambda_{t+1} \Pi_{t}\right],
\end{aligned}
$$

where $\Pi_{t} \equiv P_{t} / P_{t-1}$ denotes the gross inflation rate, and $\lambda_{t}$ denotes the Lagrange multiplier.

\subsubsection{Firms}

A continuum of domestic firms produce differentiated goods under monopolistic competition. Prices are sticky à la Calvo: only a fraction $1-\theta_{H}$ of firms can set prices optimally in a given period; the remaining fraction $\theta_{H}$ is not allowed to reoptimize its pricing plans and simply adjusts prices based on the past period's inflation rate $\pi_{H, t-1}$, as follows

$$
\log P_{H, t}(j)=\log P_{H, t-1}(j)+\gamma_{H} \pi_{H, t-1},
$$

where $0 \leq \gamma_{H} \leq 1$ denotes the degree of inflation indexation. Firms maximize the expected discounted sum of future profits

$$
E_{t} \sum_{T=t}^{\infty} \theta_{H}^{T-t} Q_{t, T} Y_{H, T}(j)\left[P_{H, t}(j)\left(\frac{P_{H, T-1}}{P_{H, t-1}}\right)^{\gamma_{H}}-\frac{W_{T}}{\varepsilon_{a, t}}\right],
$$

where $\varepsilon_{a, t}$ denotes a technology disturbance, and $Y_{H, T}(j)=\left(\frac{P_{H, t}(j)}{P_{H, T}}\left(\frac{P_{H, T-1}}{P_{H, t-1}}\right)^{\gamma_{H}}\right)^{-\varepsilon}\left(C_{H, T}+C_{H, T}^{*}\right)$ is the demand curve that firms face for their product. The term $P_{H, t}$, the aggregate domestic price level, evolves as

$$
P_{H, t}=\left[\left(1-\theta_{H}\right) P_{H, t}^{*(1-\varepsilon)}+\theta_{H}\left(P_{H, t-1}\left(\frac{P_{H, t-1}}{P_{H, t-2}}\right)^{\gamma_{H}}\right)^{1-\varepsilon}\right]^{\frac{1}{1-\varepsilon}} .
$$

Besides domestic producers, the economy is populated by retail firms, which import foreign differentiated goods and are also assumed to act as monopolistic competitors and, hence, enjoy pricing power. Even though, following Monacelli (2005), the law of one price holds at the docks, their pricing power leads to the law of one price deviations in the short run and to incomplete exchange rate pass-through. Importing firms also set prices $\grave{a}$ la Calvo, with fractions $1-\theta_{F}$ and $\theta_{F}$ optimizing or setting prices according to the indexation rule (with degree of indexation now denoted by $\gamma_{F}$ ) each period. Importing firms maximize profits

$$
E_{t} \sum_{T=t}^{\infty} \theta_{F}^{T-t} Q_{t, T} C_{F, T}(j)\left[P_{F, t}(j)\left(\frac{P_{F, T-1}}{P_{F, t-1}}\right)^{\gamma_{F}}-\Xi_{T} P_{F, T}^{*}(j)\right]
$$


subject to the demand curve $C_{F, T}(j)=\left(\frac{P_{F, t}(j)}{P_{F, T}}\left(\frac{P_{F, T-1}}{P_{F, t-1}}\right)^{\gamma_{F}}\right)^{-\varepsilon} C_{F, T}$.

The first-order conditions implied by profit maximization for domestic and importing firms are given by

$$
\begin{aligned}
E_{t} \sum_{T=t}^{\infty} \theta_{H}^{T-t} Q_{t, T} Y_{H, T}(j)\left[P_{H, t}(j)\left(\frac{P_{H, T-1}}{P_{H, t-1}}\right)^{\gamma_{H}}-\frac{\varepsilon}{\varepsilon-1} \frac{W_{T}}{\varepsilon_{a, t}}\right] & =0, \\
E_{t} \sum_{T=t}^{\infty} \theta_{F}^{T-t} Q_{t, T} C_{F, T}(j)\left[P_{F, t}(j)\left(\frac{P_{F, T-1}}{P_{F, t-1}}\right)^{\gamma_{F}}-\frac{\varepsilon}{\varepsilon-1} \Xi_{T} P_{F, T}^{*}(j)\right] & =0 .
\end{aligned}
$$

\subsubsection{Exchange Rate, Terms of Trade, Monetary Policy}

Exchange rate dynamics in the model are determined by the following uncovered interest rate parity condition

$$
E_{t} \lambda_{t+1} P_{t+1}\left[\left(1+i_{t}\right)-\left(1+i_{t}^{*}\right)\left(\frac{\Xi_{t+1}}{\Xi_{t}}\right) \phi_{t+1}\right]=0 .
$$

The condition typically restricts the differential between domestic and foreign interest rates to equal the expected depreciation of the domestic currency. In our model, given the assumption of incomplete markets, there can be a wedge in the relation, given by the risk-premium disturbance $\phi_{t}$.

The real exchange rate in the model is expressed as

$$
Q_{t}=\Xi_{t} \frac{P_{t}^{*}}{P_{t}}
$$

As in Monacelli (2005), the law of one price may not hold at all times: the law of one price gap may hence be defined as $\tilde{E}_{t} \frac{P_{t}^{*}}{P_{F, t}} \neq 1$. The terms of trade are defined as:

$$
S_{t}=\frac{P_{F, t}}{P_{H, t}}
$$

Given that the available data on the terms of trade for most countries do not exactly match the definition in the model, in the empirical analysis, we take two approaches: in the first approach, we exploit terms of trade data in the estimation and account for possible misalignments by adding an exogenous disturbance $\varepsilon_{s, t}$ (which can be alternatively interpreted as measurement error); in the second approach, we force the terms of trade to match the definition in the model and do not use a corresponding observable in the estimation (in such a case, we also omit the shock). The overall empirical conclusions are similar in the two cases.

We assume that monetary policy in the home country is well approximated by the following Taylor rule

$$
i_{t}=\rho i_{t-1}+(1-\rho)\left[\psi_{\pi} \pi_{t}+\psi_{y} y_{t}+\psi_{e, t} \Delta e_{t}\right]+\varepsilon_{m p, t}
$$


which assumes that the Bank of Korea changes policy rates to react to fluctuations in domestic output, to inflation, and to the growth rate of nominal exchange rates (as we'll explain later, we allow for structural breaks in the response to the exchange rate). The rule allows for interestrate smoothing in policy decisions. The term $\varepsilon_{m p, t}$ accounts for unsystematic deviations from the historical policy rule.

Finally, market clearing implies

$$
\begin{aligned}
Y_{H, t} & =C_{H, t}+C_{H, t}^{*}, \\
Y_{t}^{*} & =C_{t}^{*} .
\end{aligned}
$$

\subsection{Model Summary}

The model's optimality and equilibrium conditions are log-linearized around a non-stochastic steady state. The resulting log-linearized equations used in the empirical analysis are shown below:

$$
\begin{aligned}
c_{t}= & \frac{h}{1+h} c_{t-1}+\frac{1}{1+h} \widehat{E}_{t} c_{t+1}-\frac{1-h}{\sigma(1+h)}\left(i_{t}-\widehat{E}_{t} \pi_{t+1}\right) \\
& +\frac{(1-h)\left(1-\rho_{\zeta}\right)}{\sigma(1+h)} \varepsilon_{\zeta, t}, \\
y_{t}= & \left(1-\alpha_{t}\right) c_{t}+\alpha_{t} \eta\left(q_{t}+s_{t}\right)+\alpha_{t} y_{t}^{*}, \\
\pi_{t}= & \left(1-\alpha_{t}\right) \pi_{H, t}+\alpha_{t} \pi_{F, t}, \\
\pi_{H, t}= & \frac{\beta}{1+\beta \gamma_{H}} \widehat{E}_{t} \pi_{H, t+1}+\frac{\gamma_{H}}{1+\beta \gamma_{H}} \pi_{H, t-1}+ \\
& +\frac{\lambda_{H}}{1+\beta \gamma_{H}}\left[\varphi y_{t}-(1+\varphi) \varepsilon_{a, t}+\alpha_{t} s_{t}+q_{t}+\frac{\sigma}{1-h}\left(c_{t}-h c_{t-1}\right)\right], \\
\pi_{F, t}= & \frac{\beta}{1+\beta \gamma_{F}} \widehat{E}_{t} \pi_{F, t+1}+\frac{\gamma_{F}}{1+\beta \gamma_{F}} \pi_{F, t-1}+\frac{\lambda_{F}}{1+\beta \gamma_{F}}\left[q_{t}-\left(1-\alpha_{t}\right) s_{t}\right]+\varepsilon_{c p, t}, \\
e_{t}-e_{t-1}= & q_{t}-q_{t-1}+\pi_{t}-\pi_{t}^{*}, \\
\widehat{E}_{t} e_{t+1}-e_{t}= & i_{t}-i_{t}^{*}+\chi a_{t}+\varepsilon_{\phi, t}, \\
a_{t}= & \beta^{-1} a_{t-1}-\alpha_{t}\left(q_{t}+\alpha_{t} s_{t}\right)-\frac{\alpha_{t}}{1-\alpha_{t}} y_{t}+\frac{\alpha_{t}}{1-\alpha_{t}}\left[\eta\left(s_{t}+q_{t}\right)+y_{t}^{*}\right], \\
s_{t}-s_{t-1}= & \pi_{F, t}-\pi_{H, t}+\varepsilon_{s, t}, \\
i_{t}= & \rho i_{t-1}+(1-\rho)\left[\psi_{\pi} \pi_{t}+\psi_{y} y_{t}+\psi_{e, t} \Delta e_{t}\right]+\varepsilon_{m p, t} .
\end{aligned}
$$

The Equation (28) is the Euler equation for consumption under habit formation in consumers' preferences. The goods market clearing condition, expressed by Equation (29), posits a relation between domestic output and domestic consumption, the terms of trade, the real exchange rate, and global output. Equations (30) to (32) define the dynamics of inflation: CPI inflation is a weighted average of domestic and import-price inflation. Domestic inflation evolves according to a 
New Keynesian Phillips curve, with the current inflation rate driven by expected future inflation, lagged inflation, and current marginal costs. Marginal costs in the equation are a function of current output, technology shocks, the terms of trade, the real exchange rate, and current and lagged consumption. Import price inflation is driven by expectations, lagged terms, and the law of one price gap, which depends on the real exchange rate and on the terms of trade. The composite coefficients $\lambda_{H}$ and $\lambda_{F}$, which define the slope of the Phillips curves, are negative functions of the degrees of price stickiness $\theta_{H}$ and $\theta_{F}$, respectively.

Equation (33) defines the real exchange rate: changes in the nominal exchange rate equal changes in the real exchange rate plus changes in domestic inflation minus changes in foreign inflation. The main equation for the determination of exchange rates in the model is given by the log-linearized UIP condition (34): the expected depreciation of the nominal exchange rate equals the differential between home and foreign interest rates, but, given the assumption of incomplete markets, it also depends on the country's financial assets position and on the risk-premium shock $\varepsilon_{\phi, t}$. Net foreign assets evolve according to equation (35). Equation (36) defines the terms of trade: quarterly changes are equal to the differential between foreign-produced and domestic-producedgoods inflation; this is not a perfect equality, however, as we allow, at least for now, for a shock, which is meant to capture misalignments between the available data on the terms of trade and the implied theoretical variable in the model.

The final equation (37) represents a Taylor rule for an open economy. The policy rate is adjusted gradually in reaction to movements in inflation, output, and (nominal) exchange rates. Given that the exchange rate regime in Korea switches from a managed float arrangement to a floating regime in 1997, we allow for a break in the response coefficient to exchange rates. ${ }^{2}$

In the model, we replaced the mathematical expectation operator $E_{t}$ with the more flexible subjective expectation indicator $\widehat{E}_{t}$. The next subsection describes how such expectations are formed. Moreover, we let the openness parameter $\alpha$ be time-varying in the empirical section to match the increase in openness in Korea over the period.

The global, or the rest of the world (ROW), variables $\left(y_{t}^{*}, \pi_{t}^{*}, i_{t}^{*}\right.$ collected in vector $\left.X_{t}^{*}\right)$, which enter some of the main structural equations, are modeled in an unrestricted fashion as following a $\operatorname{VAR}(1)$ :

$$
X_{t}^{*}=\digamma X_{t-1}^{*}+\Omega \varepsilon_{t}^{*}
$$

where the matrix $\digamma$ contains the VAR coefficients $f_{11}, \ldots, f_{33}$ and $\Omega$ is assumed to be diagonal. ${ }^{3}$

\footnotetext{
${ }^{2}$ Taylor rules with high response coefficients to exchange rates represent a straightforward way to model actively managed or fixed exchange rate regimes (see Benigno et al. (2007)).

${ }^{3}$ We restrain from modeling the rest of the world aggregate in a structural fashion, given the heterogeneity of the
} 
There is a total of nine structural disturbances in the model: the domestic preference, technology, cost-push, monetary policy, the terms of trade, the exchange rate or interest rate risk premium, global output, global inflation, and global interest rate shocks.

\subsection{Non-Fully Rational Expectations}

We relax the strong informational assumptions implicit in the rational expectations hypothesis. The deviation from rational expectations is, however, kept small: the assumed expectation formation model is typically interpreted as 'near'-rational. Agents are assumed to form forecasts based on their Perceived Law of Motion (PLM), which has the same structural form as the Minimum State Variable (MSV) solution of the system under rational expectations. For empirical realism, we assume that agents observe historical data related to the model's endogenous variables, but they are unable to observe the structural disturbances. Such an assumption is meant to endow agents with a level of knowledge that doesn't surpass the knowledge of an economic researcher or econometrician working with the model. The agents' PLM is given by

$$
Y_{t}=a_{t}+b_{t} Y_{t-1}+\epsilon_{t}
$$

where $a_{t}$ is a vector of estimated intercepts, $b_{t}$ is a matrix of coefficients describing the perceived dynamics of the economy, and $Y_{t}=\left[c_{t}, \pi_{t}, \pi_{H, t}, \pi_{F, t}, q_{t}, s_{t}, i_{t}, a_{t}, e_{t}, y_{t}^{*}, \pi_{t}^{*}, i_{t}^{*}\right]^{\prime}$. Therefore, we allow economic agents in the small open economy to incorporate information on foreign variables to form their expectations. The PLM is written in its more general form, but it is necessary to point out that some coefficients are equal to zero: the coefficients on lagged CPI inflation are equal to zero (since they are zero in the MSV solution under RE), while the coefficients on its components, domestic and import price inflation, are non-zero. Also, as under rational expectations, domestic agents recognize that global output, inflation, and interest rates are exogenous to the domestic economy (the small open economy assumption): in the perceived equations for these global variables, the coefficients on domestic variables are restricted to zero.

Agents estimate the PLM using the available historical time series at each point in time. They update their beliefs according to the learning formulae

$$
\begin{aligned}
\widehat{\phi}_{t} & =\widehat{\phi}_{t-1}+\mathbf{g} R_{t}^{-1} X_{t}\left(Y_{t}-\widehat{\phi}_{t-1}^{\prime} X_{t}\right)^{\prime}, \\
R_{t} & =R_{t-1}+\mathbf{g}\left(X_{t} X_{t}^{\prime}-R_{t-1}\right),
\end{aligned}
$$

economies it includes. The aggregate dynamics of global variables are well represented empirically by an atheoretical VAR. The assumption of diagonality of $\Omega$, instead, is simply intended to facilitate the structural interpretation of each foreign disturbance. We have also estimated the VAR by allowing for a full $\Omega$ matrix and the results are entirely similar (the estimated correlations remain around 0.2 or below). Later, for robustness, we will also describe the results when foreign and domestic shocks are permitted to be correlated. 
where $\widehat{\phi}_{t}=\left[a_{t}, b_{t}\right]^{\prime}$ and $X_{t}=\left[1, Y_{t-1}\right]^{\prime}$. The first expression describes the updating of mean beliefs $\widehat{\phi}_{t}$ (i.e., the perceived coefficients), which collect all the relevant coefficients in $a_{t}$ and $b_{t}$, and the second the updating of the associated precision matrix $R_{t}$. Agents' expectations formed from equation (39), with beliefs that are updated via equations (40) and (41), can be substituted into the system expressed by equations (28)-(38) to yield the so-called economy's Actual Law of Motion or ALM.

\section{Estimation Details}

\subsection{State Space}

The ALM of the model can be inserted in a state-space system and written as

$$
\begin{aligned}
\xi_{t} & =A_{t}\left(\alpha_{t}, \widehat{\phi}_{t}\right)+F_{t}\left(\alpha_{t}, \widehat{\phi}_{t}\right) \xi_{t-1}+G_{t}\left(\alpha_{t}, \widehat{\phi}_{t}\right) \omega_{t} \\
\text { Observables }_{t} & =H \xi_{t}
\end{aligned}
$$

where $\xi_{t}$ collects the model's endogenous variables, the structural disturbances, and the expectation terms, and $\omega_{t}$ collects the structural innovations. The second equation in the system represents the set of measurement equations linking observables with their counterparts in the model, through the selection matrix $H$.

The vectors and matrices of coefficients $A, F$, and $G$ in the ALM are functions of the degree of openness in the economy, measured by the parameter $\alpha_{t}$, which is varying over time because of increased globalization. Figure 2 shows the degree of openness $\alpha_{t}$ over the sample. They are also time-varying because of private-sector agents' learning and evolving beliefs summarized by $\widehat{\phi}_{t}$.

The structural parameter $\alpha_{t}$ affects the dynamic interactions between the variables in the system and, in particular, the extent to which domestic conditions are sensitive to open-economy and foreign variables. By allowing for the structure of the economy to depend on the time-varying $\alpha_{t}$, we are able to investigate the impact of globalization on macroeconomic dynamics in Korea.

\subsection{Data}

We estimate the structural small open economy model using quarterly data for Korea and global variables for a sample spanning the period between 1991:I and 2012:IV. In the estimation we match the following set of observables (the corresponding variable in the model is shown in parenthesis): Korea data for real GDP $\left(y_{t}\right)$, the CPI inflation rate $\left(\pi_{t}\right)$, import price inflation $\left(\pi_{F, t}\right)$, the terms of trade $\left(s_{t}\right)$, the nominal effective exchange rate $\left(e_{t}\right)$, and a short-term nominal interest rate $\left(i_{t}\right)$, and our calculated series for global output $\left(y_{t}^{*}\right)$, global inflation $\left(\pi_{t}^{*}\right)$, and global interest rates $\left(i_{t}^{*}\right)$. 
Figure 2: Globalization in Korea: Time-Varying Degree of Openness, denoted by Coefficient $\alpha_{\mathbf{t}}$ in the Structural SOE Model.

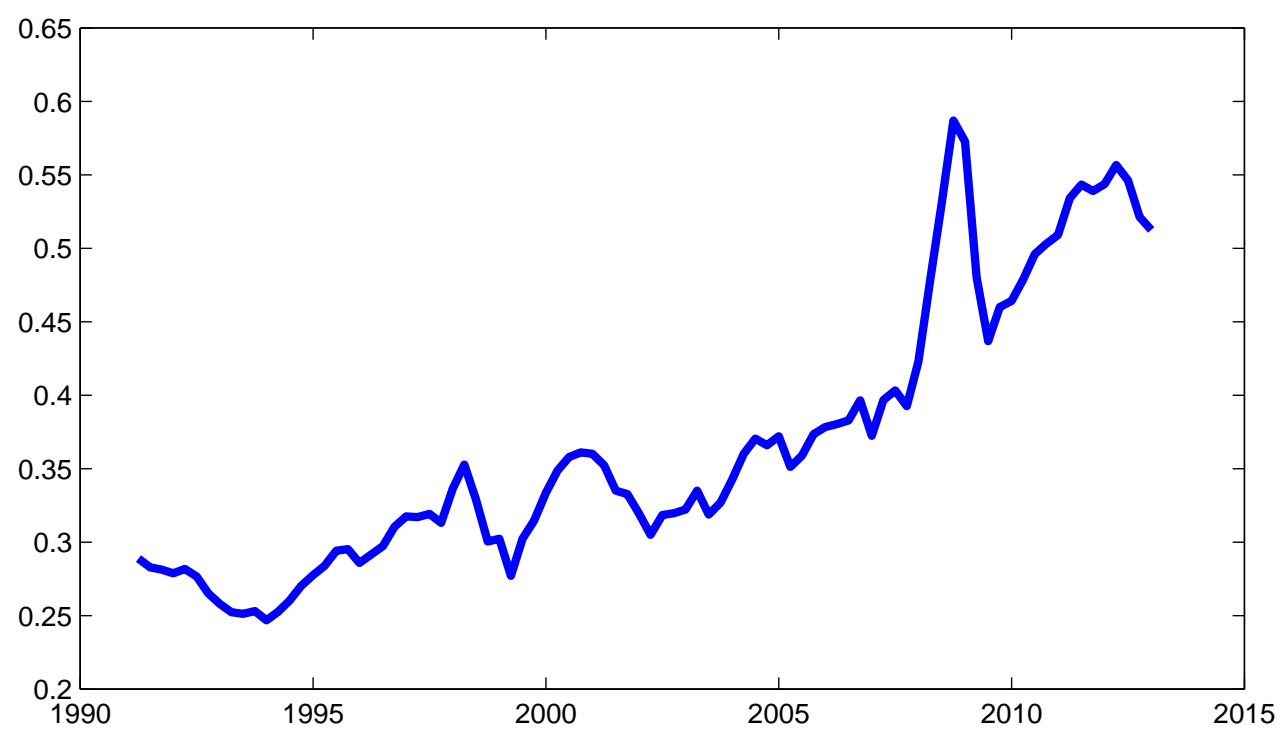

For real GDP, the terms of trade and the exchange rate, given their non-stationarity in the sample, we consider their linearly-detrended counterparts in the estimation. CPI and import price inflation are computed as the quarterly log difference in the respective price indices. For the exchange rate, we use the nominal effective exchange rate published by the Bank for International Settlements in which an increase in value denotes an appreciation. Therefore, we adjust the original exchange rate series for an increase in value to denote a depreciation. As the nominal interest rate represents the domestic central bank's policy rate in the model, we use the call rate, expressed as quarterly rate.

We need to construct the relevant global output, global inflation, and global interest rates measures. We construct them selecting the major 24 trading partners of Korea in each period: altogether they account for the vast majority of the country's trade with the rest of the world. The trading partners we include are (in alphabetical order): Australia, Brazil, Canada, China, England, France, Germany, Hong Kong, India, Indonesia, Italy, Japan, Malaysia, the Netherlands, Panama, the Philippines, Russia, Saudi Arabia, Singapore, Switzerland, Taiwan, Thailand, the United Arab Emirates, and USA. We construct time-varying weights for each trading partner based on their import and export share with Korea as a fraction of total imports and exports with the selected set of partners in each period. In the few cases in which observations on GDP, inflation, or interest rates for the trading partner are not available in a given quarter (which happens for some countries in the early part of the sample), we assign them a zero weight and, hence, exclude them from 
the computation of the relevant global measure in that period. The impact of occasional missing data on the results should be minimal, given that data are available for the major trading partners (USA, Japan, China, Germany, etc.).

Given that we consider linearly detrended domestic GDP, we use the same detrending procedure for global GDP. We linearly detrend real GDP series for each trading partner using the available samples. Global inflation are computed as the quarterly log difference in the price index and interest rates are considered in levels (as quarterly rates). We choose seasonally adjusted data when available and, when they are not, we run the seasonal adjustment procedure on the raw series (except for interest rates). Global measures are computed as weighted averages as:

$$
\begin{aligned}
y_{t}^{*} & =\sum_{j=1}^{N} w_{t}^{y, j} y_{t}^{j}, \\
\pi_{t}^{*} & =\sum_{j=1}^{N} w_{t}^{\pi, j} \pi_{t}^{j}, \\
i_{t}^{*} & =\sum_{j=1}^{N} w_{t}^{i, j} i_{t}^{j},
\end{aligned}
$$

where $j=1, \ldots, N, N=24$, is an index for the different trading partners, $y_{t}^{j}, \pi_{t}^{j}$, and $i_{t}^{j}$ are the detrended output, inflation rate, and short-term interest rate, of trading partner $j$, and where the weights $w_{t}^{z, j}$, for variable $z=y, \pi, i$, are given in each period $t$ by the sum of Korea's imports and exports with country $j$, as a fraction of total Korean imports and exports with the set of trading partners: ${ }^{4}$

$$
w_{t}^{z, j}=\frac{\left(\text { Imports }_{t}^{j}+\text { Exports }_{t}^{j}\right)}{\sum_{i=1}^{N}\left(\text { Imports }_{t}^{j}+\text { Exports }_{t}^{j}\right)} .
$$

Figure 3 shows the resulting series for (detrended) global output, global inflation, and global interest rates, along with the six domestic variables used in the estimation. The global series are mostly influenced by Japanese and U.S. economic fundamentals in the first part of the sample, and they become progressively more sensitive to Chinese economic developments in the latter part of the sample. Time-varying weights for the major trading partners (Japan, U.S., China, and a combination of European partners) are shown in Figure 4.

\footnotetext{
${ }^{4}$ The only reason why the weights may differ across variables is because possibly different observations may be missing for GDP, inflation, or interest rates, for the different countries. As discussed before, when an observation for a country is missing, that country is assigned a zero weight in the computation of the global measure in that period.
} 
Figure 3: Data Series used in the Estimation.
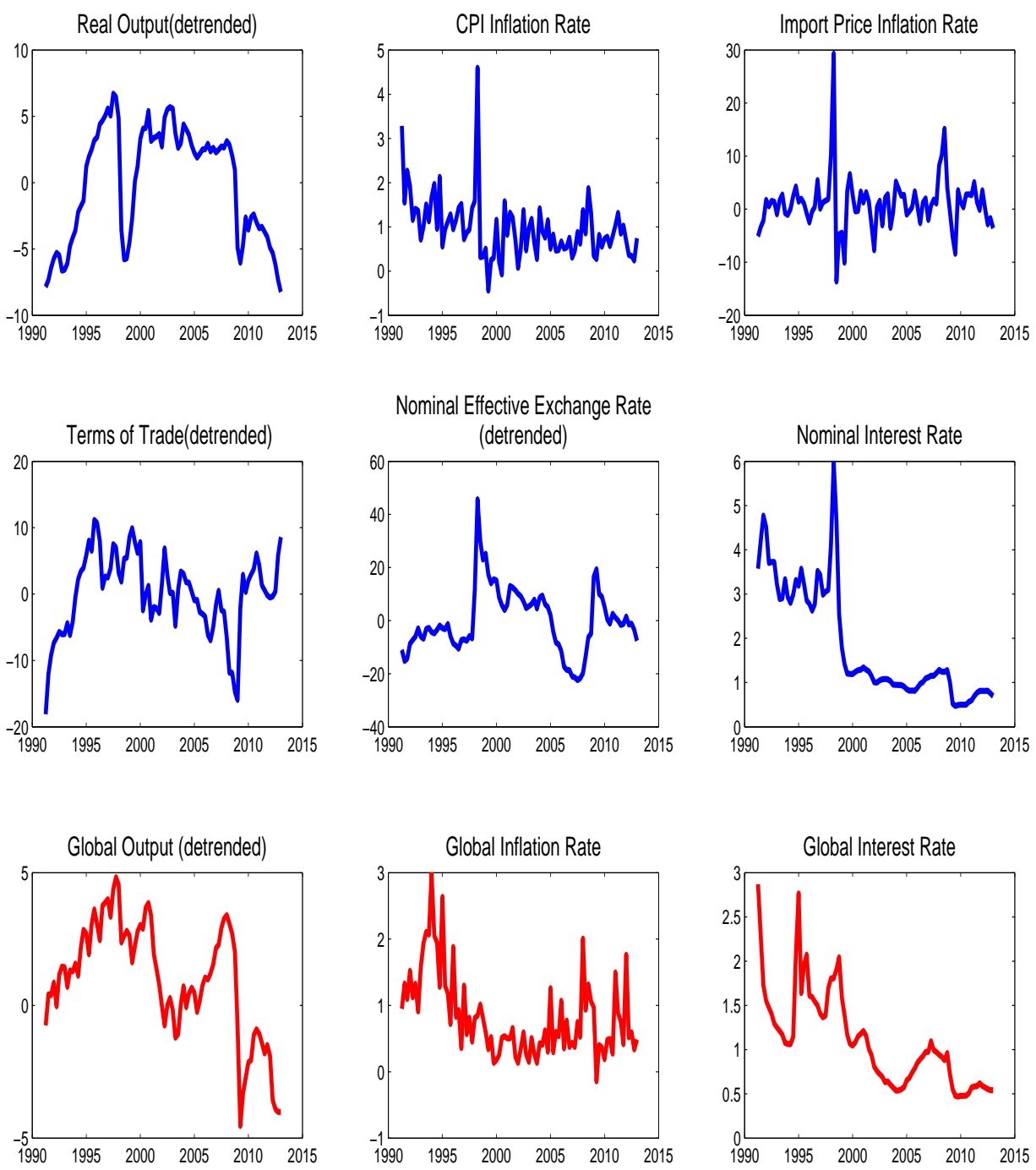

\subsection{Bayesian Approach}

The model is estimated using Bayesian techniques. We start by eliciting priors for the model coefficients that will be estimated; the prior distributions are shown in Table 1.

In the estimation under learning, we also need to make assumptions about the initialization of the learning process. While the effect of initial beliefs typically disappears after a number of periods, it can affect the dynamics of the economy in the early part of the sample. We adopt a relatively agnostic solution here: we initialize the agents' learning process with PLM coefficients that are 
Figure 4: Time-Varying Major Trading Partners' Weights.

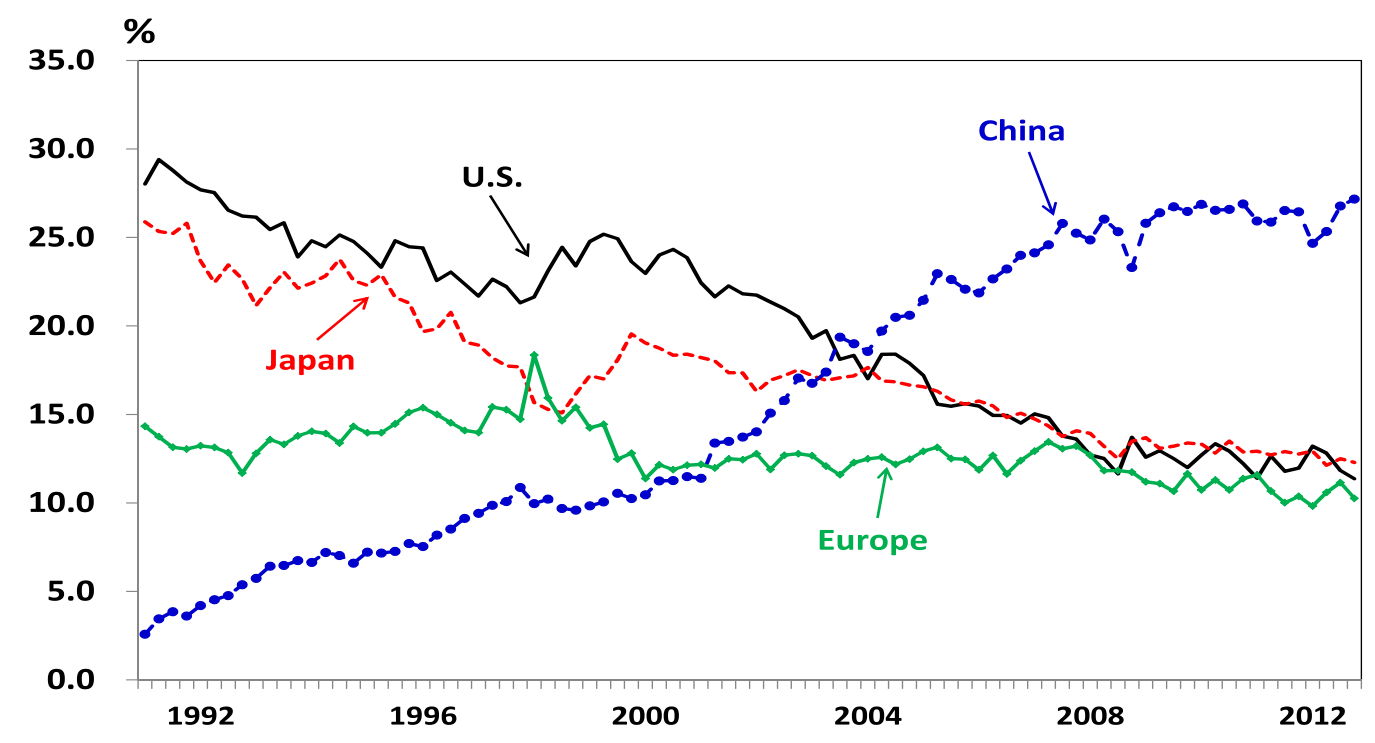

obtained by fixing the DSGE coefficients at their prior means and solving the model under rational expectations. The reason we use prior means, instead of posterior means, for initialization is because we find it unrealistic to endow agents with knowledge of posterior estimates at the beginning of the sample (for which they would need to observe data from 1991 to 2012, which cannot be available in 1991). Therefore, agents start their learning process with beliefs that are equal to the values they would assume under the model's implied Rational Expectations Equilibrium (REE). The results are presented under this benchmark initialization. In the robustness section, we will repeat the estimation with an arbitrary and even more agnostic initialization by fixing all initial beliefs equal to zero, except the perceived autoregressive parameters, which are assumed to start from 0.9.

We obtain draws from the posterior distribution using a Metropolis-Hastings algorithm. We drop the initial $25 \%$ of draws as burn-in. Posterior means and $95 \%$ posterior density intervals are presented in the estimation tables.

\section{Results}

\subsection{Structural Estimates}

Table 1 reports the posterior estimates for the baseline model. There is typically a large uncertainty in the literature on the values assumed by $\eta$, the elasticity of substitution across domestic and foreign goods, with values ranging from close to zero (particularly in estimations) to much 
Table 1: Prior Distributions and Posterior Estimates, Baseline Model.

\begin{tabular}{|c|c|c|c|}
\hline Parameters & Prior Distributions & "Posterior Mean & $95 \%$ PDI \\
\hline$\eta$ & $\Gamma(2,0.25)$ & 0.47 & {$[0.36,0.60]$} \\
\hline$h$ & $B(0.7,0.1)$ & 0.70 & {$[0.48,0.85]$} \\
\hline$\sigma$ & $\Gamma(1.5,0.25)$ & 1.40 & {$[0.92,1.91]$} \\
\hline$\gamma_{H}$ & $B(0.7,0.1)$ & 0.64 & {$[0.40,0.83]$} \\
\hline$\theta_{H}$ & $B(0.75,0.1)$ & 0.82 & {$[0.61,0.93]$} \\
\hline$\varphi$ & $\Gamma(1.5,0.125)$ & 1.52 & {$[1.29,1.75]$} \\
\hline$\gamma_{F}$ & $B(0.7,0.1)$ & 0.51 & {$[0.27,0.77]$} \\
\hline$\theta_{F}$ & $B(0.75,0.1)$ & 0.29 & {$[0.23,0.35]$} \\
\hline$\chi$ & $\Gamma(0.01,0.005)$ & 0.009 & {$[0.003,0.02]$} \\
\hline$\rho$ & $B(0.7,0.1)$ & 0.83 & {$[0.78,0.89]$} \\
\hline$\psi_{\pi}$ & $N(1.5,0.125)$ & 1.63 & {$[1.40,1.86]$} \\
\hline$\psi_{y}$ & $N(0.25,0.125)$ & 0.11 & {$[0.02,0.22]$} \\
\hline$\psi_{\Delta e, \leq 97}$ & $\Gamma(0.75,0.3)$ & 0.39 & {$[0.23,0.62]$} \\
\hline$\psi_{\Delta e, \geq 98}$ & $\Gamma(0.15,0.15)$ & 0.13 & {$[0.05,0.27]$} \\
\hline$\rho_{z}$ & $B(0.5,0.2)$ & 0.33 & {$[0.14,0.53]$} \\
\hline$\rho_{a}$ & $B(0.5,0.2)$ & 0.23 & {$[0.06,0.58]$} \\
\hline$\rho_{c p}$ & $B(0.5,0.2)$ & 0.79 & {$[0.67,0.90]$} \\
\hline$\rho_{s}$ & $B(0.5,0.2)$ & 0.33 & {$[0.16,0.52]$} \\
\hline$\rho_{\phi}$ & $B(0.5,0.2)$ & 0.68 & {$[0.50,0.81]$} \\
\hline$\sigma_{z}$ & $\Gamma^{-1}(0.5,2)$ & 3.84 & {$[3.17,4.75]$} \\
\hline$\sigma_{a}$ & $\Gamma^{-1}(0.5,2)$ & 1.14 & {$[0.94,1.48]$} \\
\hline$\sigma_{c p}$ & $\Gamma^{-1}(0.5,2)$ & 8.72 & {$[7.04,10.88]$} \\
\hline$\sigma_{s}$ & $\Gamma^{-1}(0.5,2)$ & 8.85 & {$[7.75,10.13]$} \\
\hline$\sigma_{\phi}$ & $\Gamma^{-1}(0.5,2)$ & 6.57 & {$[5.66,7.61]$} \\
\hline$\sigma_{m p}$ & $\Gamma^{-1}(0.5,2)$ & 0.29 & {$[0.25,0.33]$} \\
\hline$f_{11}$ & $B(0.8,0.1)$ & 0.94 & {$[0.87,0.98]$} \\
\hline$f_{12}$ & $N(0,0.25)$ & -0.09 & {$[-0.34,0.15]$} \\
\hline$-f_{13}$ & $\Gamma(-0.25,0.15)$ & 0.14 & {$[0.03,0.30]$} \\
\hline$f_{21}$ & $\Gamma(0.1,0.05)$ & 0.05 & {$[0.02,0.09]$} \\
\hline$f_{22}$ & $B(0.5,0.2)$ & 0.53 & {$[0.35,0.71]$} \\
\hline$f_{23}$ & $N(0,0.25)$ & 0.07 & {$[-0.15,0.28]$} \\
\hline$f_{31}$ & $\Gamma(0.1,0.05)$ & 0.04 & {$[0.02,0.09]$} \\
\hline$f_{32}$ & $\Gamma(0.1,0.05)$ & 0.06 & {$[0.02,0.11]$} \\
\hline$f_{33}$ & $B(0.8,0.1)$ & 0.78 & {$[0.67,0.88]$} \\
\hline$\sigma_{y *}$ & $\Gamma^{-1}(0.5,1)$ & 0.85 & {$[0.72,0.99]$} \\
\hline$\sigma_{\pi *}$ & $\Gamma^{-1}(0.5,1)$ & 0.50 & {$[0.43,0.59]$} \\
\hline$\sigma_{i *}$ & $\Gamma^{-1}(0.5,1)$ & 0.21 & {$[0.18,0.25]$} \\
\hline$\overline{\mathrm{g}}$ & $B(0.025,0.005)$ & 0.009 & {$[0.006,0.012]$} \\
\hline
\end{tabular}

Note: $\Gamma$ denotes Gamma distribution, $B$ Beta distribution, $N$ Normal distribution, and $\Gamma^{-1}$ Inverse Gamma distribution. The prior distributions are expressed in terms of mean and standard deviation.

higher (in calibrations). Here, we find a posterior mean estimate equal to 0.47 , which is in line with many estimates for other countries, although lower than typical calibration choices. Regarding nominal rigidities, there is substantial evidence of price stickiness for firms producing domestic goods, with a mean for the Calvo coefficient $\theta_{H}$ equal to 0.82 ; the degree of stickiness in the import 
sector is, instead, quite limited, with a Calvo coefficient $\theta_{F}$ estimated at 0.29 . Such value implies a non-trivial, although imperfect, degree of exchange-rate pass-through.

The posterior estimates regarding the Bank of Korea's monetary policy rule indicate an aggressive response toward fluctuations in CPI inflation $\left(\psi_{\pi}=1.63\right)$, a more limited response to real activity $\left(\psi_{y}=0.11\right)$. The estimates also signal an attention toward exchange rate movements, with a reaction coefficient to the growth rate of the nominal exchange rate $\psi_{\Delta e}$ that shifts from 0.39 in the managed float pre-crisis period to 0.13 after 1997 (the latter obtained under a prior distribution favoring values close to zero).

The persistence of the structural disturbance hitting the economy is not extreme: the autoregressive coefficients are estimated at values between 0.23 and 0.79 . The shocks, however, have a high volatility, and particularly so the open-economy shocks to import price, the terms of trade, and the risk premium.

Finally, we have also estimated the constant gain coefficient, which is responsible for governing the speed at which agents learn about the structure of the economy, along with the other 'deep' parameters of the model. We find a posterior mean for the constant gain equal to 0.009, with a value that is somewhat smaller than the ones typically found for the U.S. (e.g., Milani (2007), Milani (2011)).

\subsection{Globalization and Macroeconomic Dynamics}

As a result of globalization, the relationships between macroeconomic variables in Korea and in the rest of the world may change in magnitude over the sample. Figure 5 shows the implied reduced-form coefficients, i.e. the relevant elements in the matrix $F_{t}\left(\alpha_{t}, \widehat{\phi}_{t}\right)$, describing some of the most interesting relationships. For each panel, the figure shows the posterior mean estimate of the composite reduced-form coefficient over the sample, along with the $5 \%$ and $95 \%$ bands. The main change which is apparent from the figure is that Korea's output has become much more responsive to global measures of slack over time, as $y_{t}$ has become more and more driven by $y_{t}^{*}$, and less influenced by domestic demand, with the effect of domestic consumption on output falling over time. The effect of open-economy variables, as the terms of trade and the real exchange rate, on real activity has also increased over the sample.

The recent literature on globalization and the role of global slack for macroeconomics and monetary policy has mostly focused on the increased significance of global slack as a driver of domestic inflation rates. While the evidence for such countries as the U.S. is mixed, the evidence is clearly more favorable for Korea: the dependence of $\pi_{t}$ on global output has risen from values close to 0.09 
Figure 5: Time-Varying Reduced-Form Coefficients.
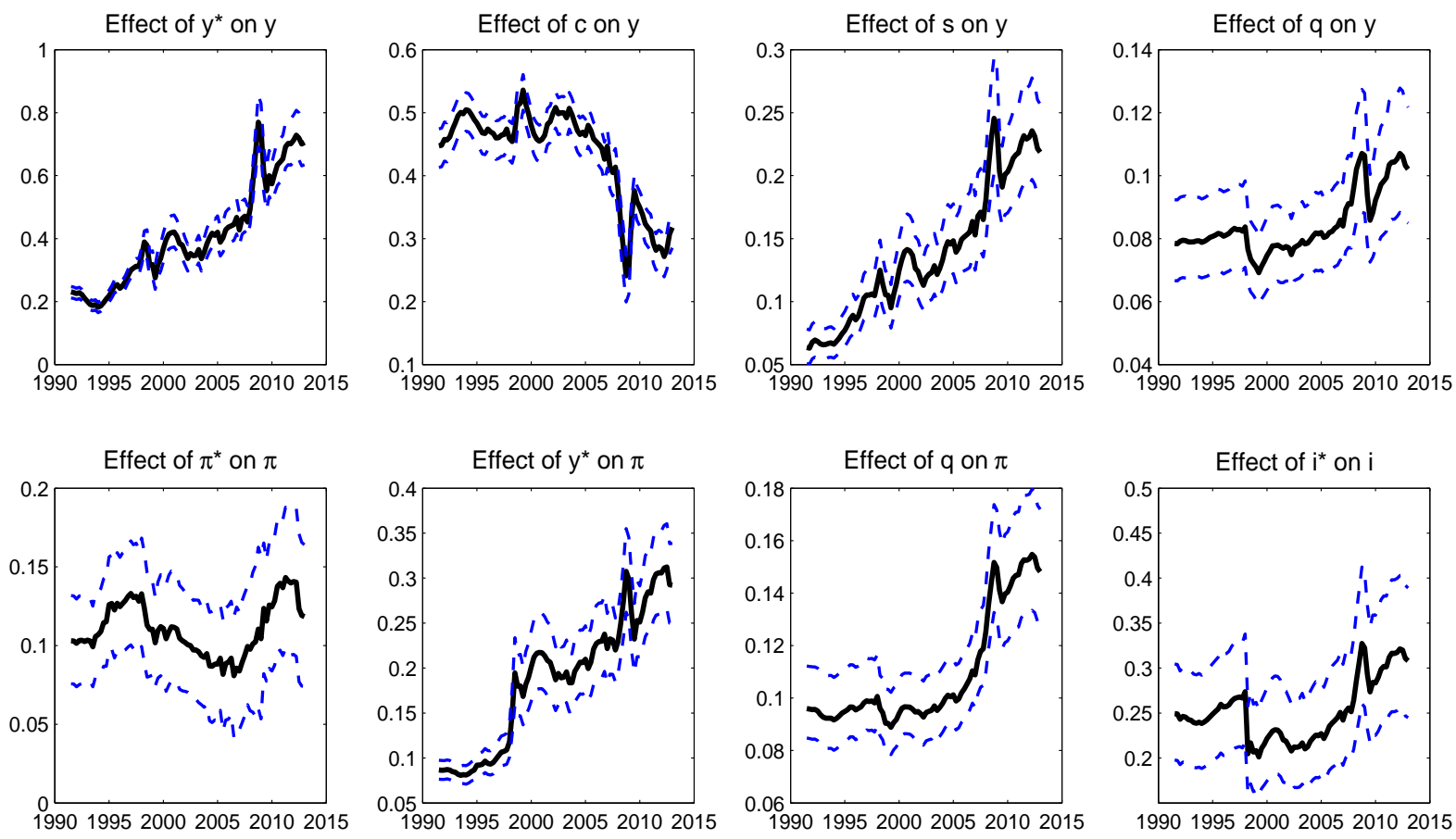

Note: The graphs show posterior means across draws for the composite reduced-form coefficients, along with $5 \%$ and $95 \%$ percentile bands.

to around 0.3 in 2012. The effect is also quite precisely estimated. Inflation also has become more sensitive to exchange rates over time. The only relationship that doesn't seem to have consistently changed over time is the one between domestic and global inflation: we may speculate that the estimated coefficient's movement toward zero may be a consequence of the overall stability of inflation rates around the world in the second part of the sample.

It is worth reminding that the reduced-form interactions in the economy are time-varying not only as a result of globalization, but also as a result of the variation in agents' beliefs due to their incremental learning process about the economy. To separate the two influences, Figure 6 shows the previous time-varying coefficients along with the new counterfactual paths (shown in red) that they would have followed if the globalization channel was shut down. In such a case, the degree of openness in Korea's economy is fixed at its value at the beginning of the sample (roughly $28 \%$ in 1990) and not allowed to change afterwards. The graphs clearly show that the dependence of Korean macroeconomic variables on their global counterparts would have been significantly 
diminished, had globalization not taken place. Domestic output would be much more dependent on domestic consumption than on global output (with coefficients moving from 0.7 to 0.4 for global output, and from 0.3 to 0.5 for consumption), the sensitivity of inflation to global slack would be cut almost in half, and the role of the terms of trade and the real exchange rate in the economy would be scaled down.

Figure 6: Comparison of Time-Varying Reduced-Form Coefficients with and without Globalization.
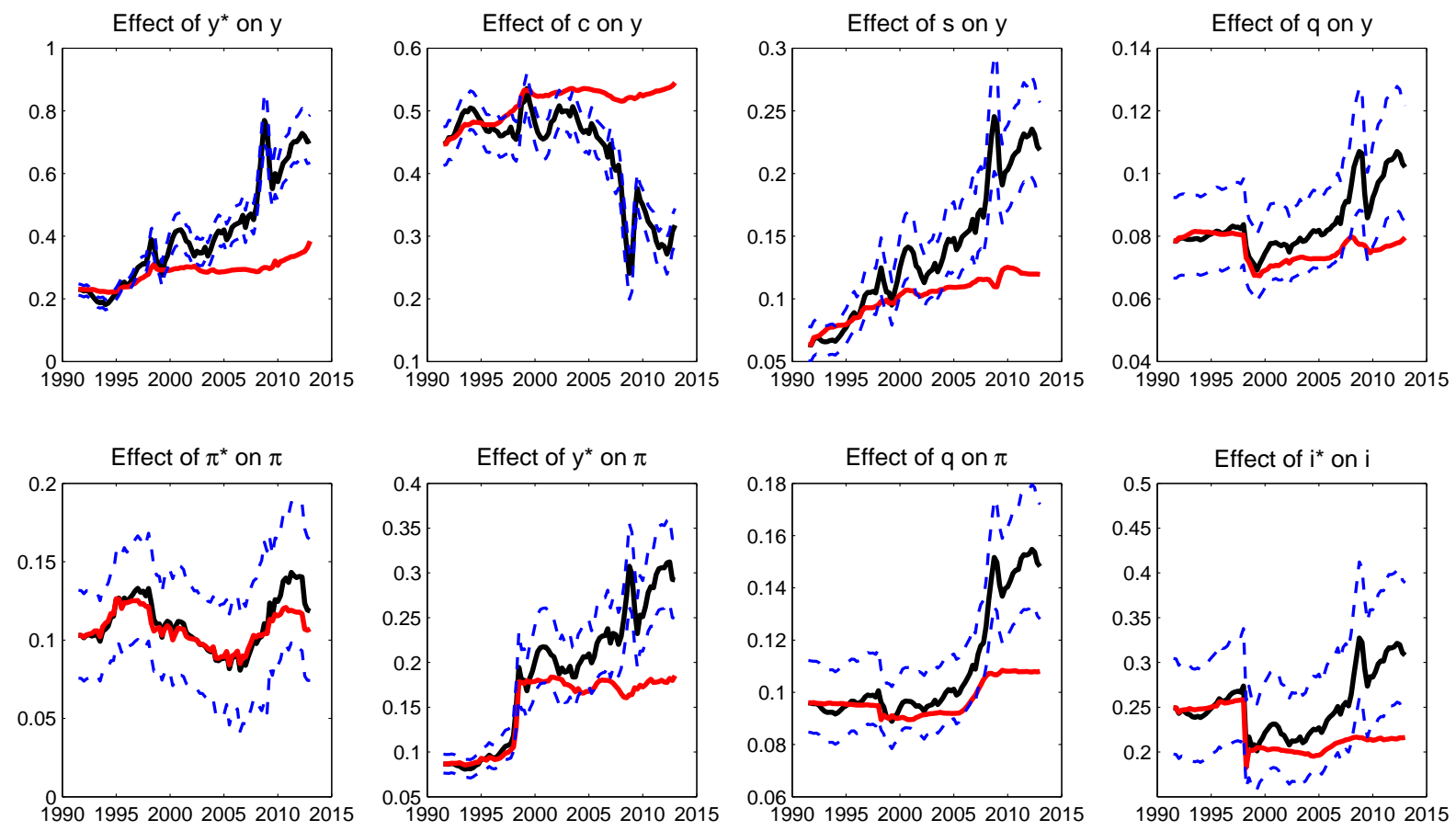

Note: The graphs show posterior means across draws for the composite reduced-form coefficients, along with $5 \%$ and $95 \%$ percentile bands. The red lines represent the counterfactual coefficients that would be obtained in the same model, if globalization hadn't taken place ( $\alpha$ constant and fixed to its value in 1990).

\subsection{The Role of Domestic and Global Shocks}

Figure 7 displays a selection of impulse responses for the main variables of interest to domestic and global shocks. The figure shows how the impulse responses vary across the sample period from 1991:I to 2012:IV. The top-left panel in the Figure highlights one of the main changes affecting the Korean economy over the sample: the response of domestic output to global output shocks has constantly increased over the sample, and it is around two times larger in 2012 than it was in 1991. Domestic real activity has also become more responsive to terms of trade and exchange rate shocks (the top-right panel and the mid-left panel in the Figure). 
Domestic Output to Global Output Shock

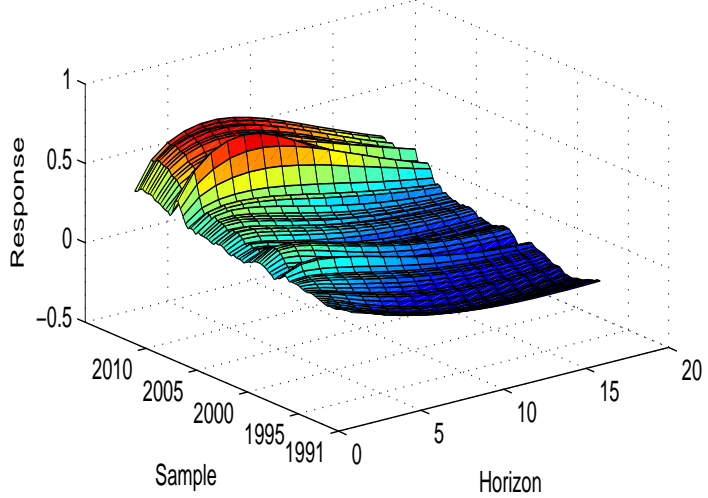

Domestic Output to Exchange-Rate Shock

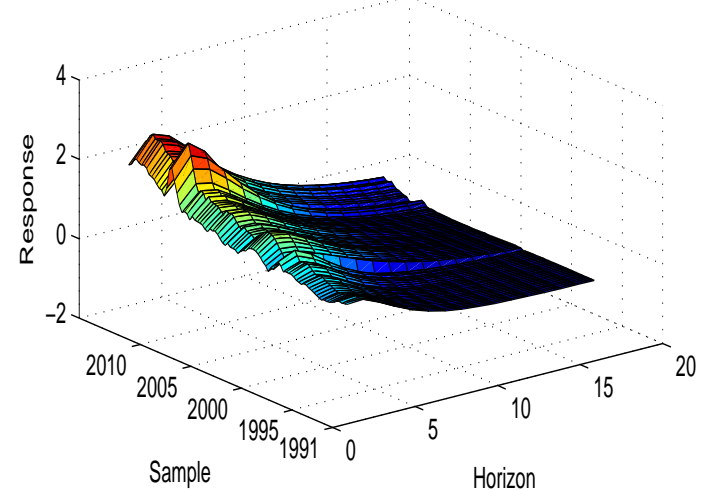

Domestic Inflation to Technology Shock

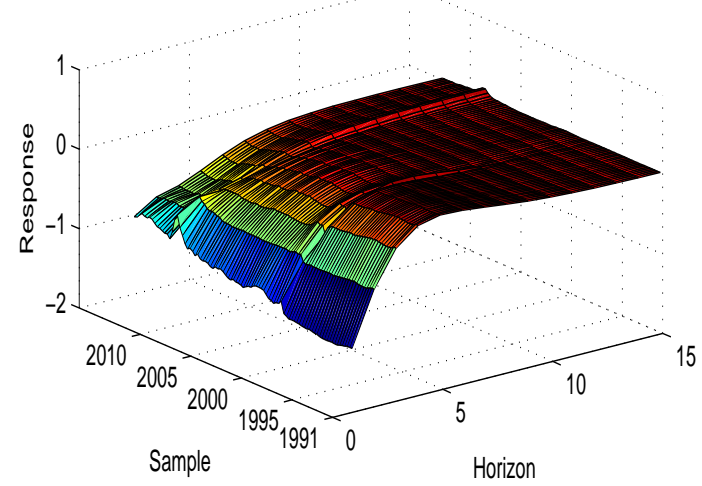

Domestic Output to Terms of Trade Shock

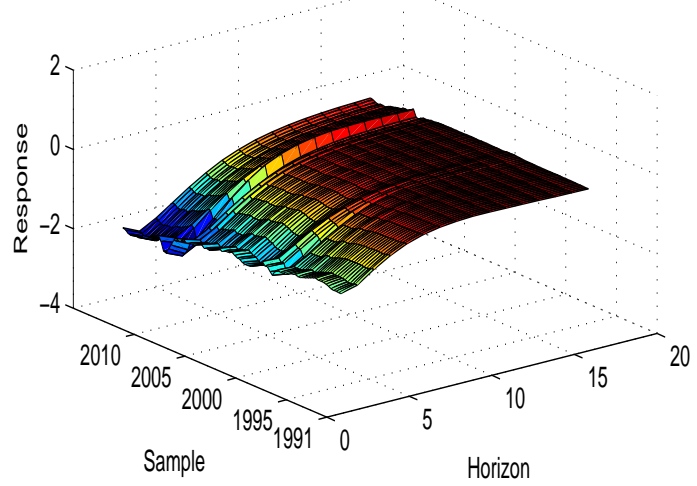

Domestic Inflation to Global Output Shock

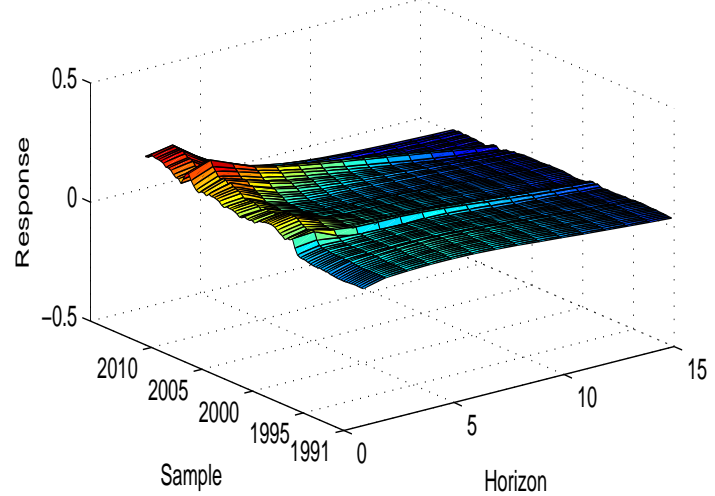

Domestic Interest Rate to Global Interest Rate Shock

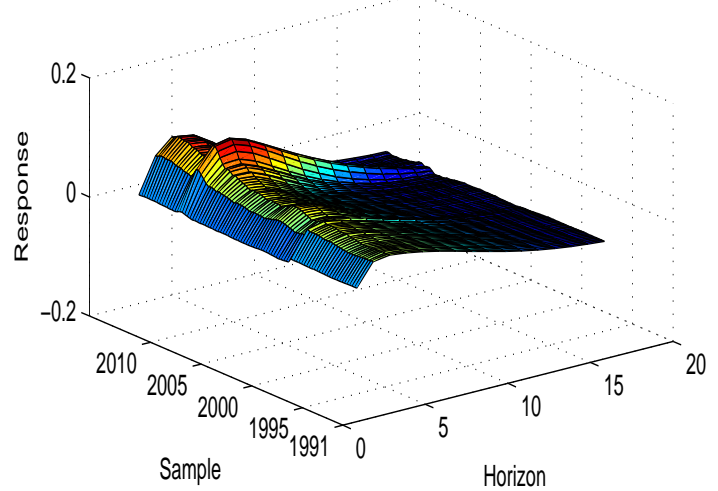




\section{Figure 8: Time-Varying Effects of Monetary Policy}

Domestic Output to Monetary Policy Shock

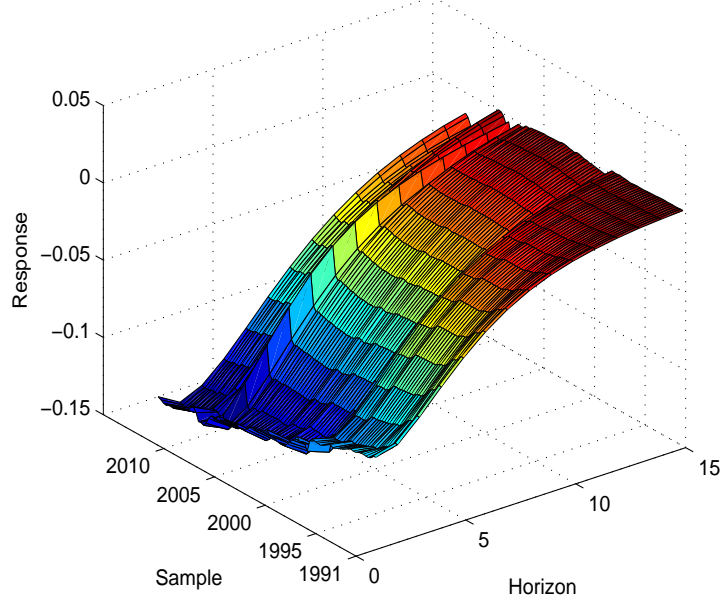

Domestic Inflation to Monetary Policy Shock

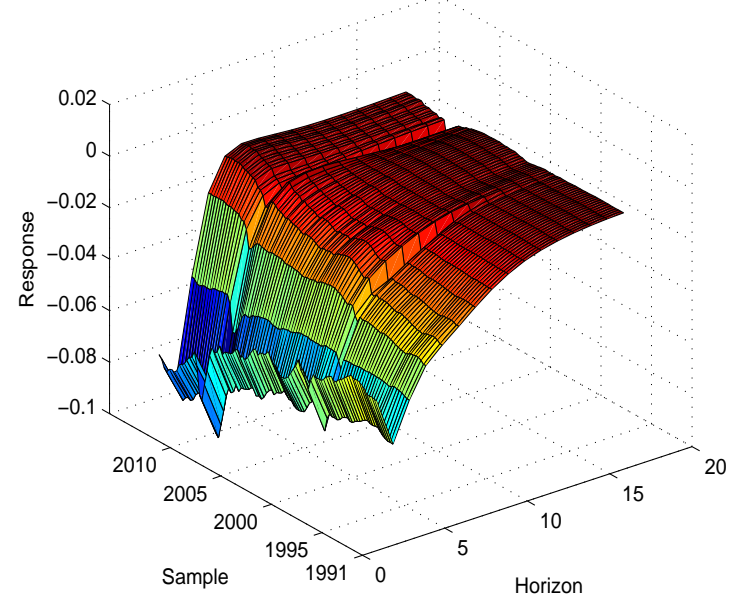

The mid-right panel and the bottom-left panel in the Figure present the corresponding evidence for inflation. Global output shocks have had a progressively larger effect on inflation over the sample, with a peak response that increased from less than 0.1 in 1991 to 0.25 in 2012, while domestic technology shocks have seen their effects halve over the period.

Finally, another noticeable change is that domestic nominal interest rates have become much more reactive to shocks affecting global interest rates than they were in the earlier decades (the bottom-right panel in the Figure).

A central source of interest in the impact of globalization on the macroeconomy is the idea that globalization may hinder the effectiveness of domestic monetary policies when the economy is influenced by global variables. We assess the evidence on changes in monetary policy effectiveness by looking at the effects of exogenous monetary policy shocks over the sample. Even though global conditions have progressively become more important, domestic monetary policy in Korea has remained effective. Figure 8 clarifies that its effects remain very similar at each point in the sample.

Given the importance of global variables and shocks documented so far, we can ask the following, possibly more general, questions: what shares of business cycle, inflation, and interest rate fluctuations in Korea are due to global, rather than domestic, forces? How much have these shares changed over time as a consequence of globalization? 
Figure 9: Forecast Error Variance Decomposition over Time
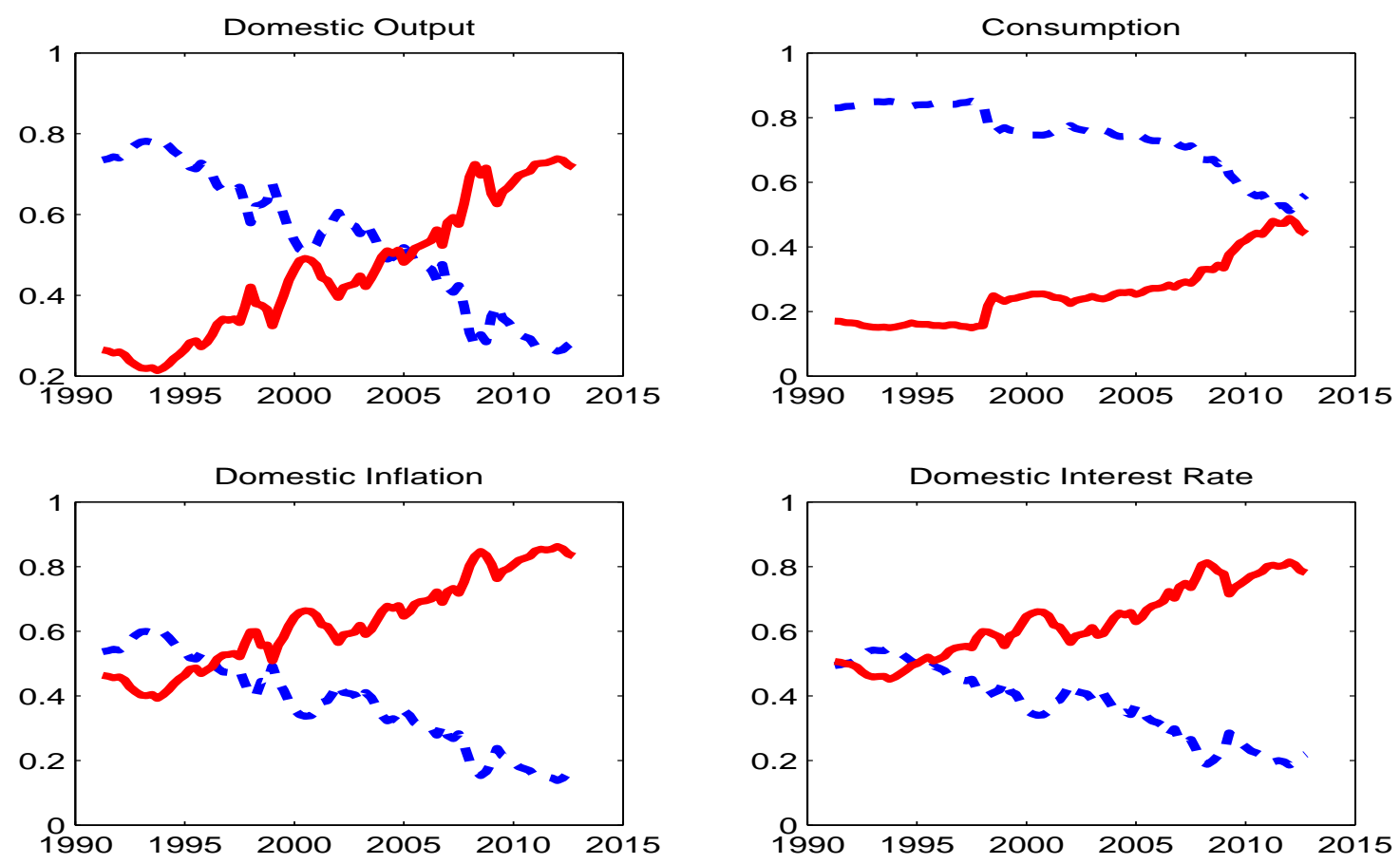

Note: The solid red line represents the share of variance explained by global (global output, global inflation, global interest rates, importing price, exchange rate and terms of trade) shocks while the dotted blue line represents the share of variance explained by domestic (techonology, preference, and monetary policy) shocks.

We answer these questions by presenting evidence from a (forecast error) variance decomposition exercise. Figure 9 illustrates the variance shares of Korea's output, consumption, inflation, and interest rate that can be accounted for by global and domestic shocks. ${ }^{5}$ Given that the variance decomposition results are also time-varying, the figure shows how the shares evolve every quarter from 1991 to 2012.

Business cycle fluctuations at the beginning of the sample are mostly driven by domestic shocks (largely preference and technology shocks), which account for more than $70 \%$ of output variability, with a limited role for global variables. The situation strongly reverses by the end of the sample: now Korean business cycles are driven by global shocks (with a share equal to $70 \%$ ), with a smaller role for domestic innovations.

As expected, consumption expenditures are still dominated by domestic shocks, mostly to consumers' preferences, but the influence of global drivers has rapidly increased over the sample, accounting for almost half of the variance by the end of the sample.

\footnotetext{
${ }^{5}$ We adopt here a flexible definition of "global" we include not only global shocks to world output, inflation, and interest rates, but also shocks related to the country's open-economy dimension, such as terms of trade, exchange rate, and import cost-push shocks.
} 
The transforming impact of globalization is also evident in the evolution of the variance decomposition shares for inflation and interest rates. While the variables are mainly driven by domestic shocks in the early 1990s, the role of global shocks becomes dominant starting from the late 1990s - early 2000s, and by 2012, global and open-economy-related shocks explain about $80 \%$ of inflation and interest rate fluctuations.

Therefore, overall our findings indicate that globalization had a transforming impact on Korea's economy. In the early stages of globalization, several economic commentators and policymakers argued that globalization would significantly alter the behavior of countries' output growth and inflation rates. Early studies revealed a positive effect of globalization on the economic environment: Romer (1993) and Rogoff (2003) relate the widespread fall in inflation rates around the world to globalization, and discuss how it reduces the incentives of central banks to inflate. The subsequent research on the topic, however, has found effects that are far more limited than initially expected. ${ }^{6}$ Most of these studies focused on the impact of globalization on the U.S. economy. Our results, instead, validate some of the initial claims by showing that globalization indeed caused larger changes on economic dynamics in a more open economy as Korea.

\section{Robustness}

To assess the sensitivity of our main results to some of the choices that have been made in the empirical analysis, we repeat the estimation considering the following six modifications. The posterior estimates under these robustness checks are shown in Table 2.

Initial Learning Beliefs. The first modification relates to the choice of initial beliefs for the agents' learning algorithm. Rather than assuming that they start with beliefs fixed at their values in a REE obtained with the model's coefficients equal to their prior means, we now assume an uninformative, although ad hoc, initialization. We fix all initial beliefs, except the coefficients of a variable on its own first lag, to be equal to zero. The autoregressive coefficients are assumed to start at a value of 0.9 at the beginning of the sample in 1991. Such initialization is somewhat in the spirit of Minnesota priors in the VAR literature (although with 0.9 rather than 1 as first-lag coefficients) and it attempts to capture the general ignorance of economic agents about the structure of the economy, along with the knowledge that macroeconomic time series are generally quite persistent.

Terms of Trade. Secondly, we change our treatment of the terms of trade variable. In the benchmark estimation, we used data on the terms of trade, obtained as the log difference between

\footnotetext{
${ }^{6}$ Examples of studies that find an overall limited impact of globalization are Ihrig et al. (2010), Milani (2012), Martinez-Garcia and Wynne (2012), and Woodford (2007), among others.
} 
the price of exports and the price of imports, as one of the observable variables to match. In the model, however, the terms of trade are given by the difference between $\pi_{F, t}$ and $\pi_{H, t}$. By using the empirical measure, instead, we have allowed for differences between the two through the exogenous disturbance $\varepsilon_{s, t}$. An alternative, which we consider here, is to take the model at heart, rather than using outside data, simply letting terms of trade equal to their definition in the model. In this case, we have eight observables and eight shocks in the estimation, rather than nine and nine. The empirical literature has been split about using the first or the second approach regarding the terms of trade.

Post-1997 Sample. Given that the Korean economy is likely subject to a structural break, at least in the monetary and exchange rate policy strategy in the aftermath of the 1997 financial crisis, we repeat the estimation on a shorter, single-regime, sample, now starting in 1998:I and ending in 2012:IV. In this case, we do not need to assume a break in the feedback coefficient to the nominal exchange rate in the Taylor rule.

Taylor Rule Dependence on Foreign Interest Rate. As a further sensitivity check, we allow for monetary policy decisions to be influenced by the global monetary policy stance. In this scenario, interest rate policies in the U.S., Japan, China, and the Euro area could have a particular effect on Korea's interest rates. We re-estimate the model using this version of the Taylor rule

$$
i_{t}=\rho i_{t-1}+\rho^{*} i_{t-1}^{*}+(1-\rho)\left[\psi_{\pi} \pi_{t}+\psi_{y} y_{t}+\psi_{e} \Delta e_{t}\right]+\varepsilon_{m p, t}
$$

where domestic interest rates can also respond to foreign interest rates through the reaction coefficient $\rho^{*}$ (for which we assume a $\operatorname{Beta}(0.5,0.2)$ prior). For this case, we also restrict the sample to the post-1997 period.

Habits with Longer Memory. In our benchmark specification, we assumed that households derive utility from the deviation of consumption from a reference level, which is simply a function of lagged, $t-1$, consumption. Although common, this specification may cause consumption to be too sensitive to unusual conditions in the previous period. Here we consider a specification, which models the stock of habits as a declining weighted average of past consumption levels, following Fuhrer (2000). Household now maximize the utility function

$$
E_{0} \sum_{t=0}^{\infty} \beta^{t} \tilde{\zeta}_{t}\left[\frac{\left(C_{t}-h H_{t-1}\right)^{1-\sigma}}{1-\sigma}-\frac{N_{t}^{1+\varphi}}{1+\varphi}\right]
$$

where the habits stock $H_{t}$ evolves as

$$
H_{t}=\rho_{h} H_{t-1}+\left(1-\rho_{h}\right) C_{t-1}
$$


The coefficient $h$ denotes the strength of habit formation motives as before, whereas the new coefficient $\rho_{h}$ measures the degree of memory in habit formation: if $\rho_{h}$ is equal to 0 , preferences revert to those in the benchmark model; in general, the weights attributed to past consumption levels decline geometrically as $\left(1-\rho_{h}\right) \sum_{j=0}^{\infty} \rho_{h}^{j} C_{t-j}$. In the estimation, we assume for $\rho_{h}$ an uninformative $U[0,1]$ prior.

Correlated Domestic and Foreign Shocks. It is reasonable to imagine that the global shocks hitting the Korean economy may not necessarily be uncorrelated with their domestic counterparts. We repeat the estimation by allowing for a non-zero correlation between shocks originating abroad and in Korea; in particular, we allow for correlation in the demand shocks $\varepsilon_{\zeta, t}$ and $\varepsilon_{y^{*}, t}$, the supply shocks $\varepsilon_{a, t}$ and $\varepsilon_{\pi^{*}, t}$, and the monetary policy shocks $\varepsilon_{m p, t}$ and $\varepsilon_{i^{*}, t}$. We denote the new correlation coefficients $\rho_{\zeta, y^{*}}, \rho_{a, \pi^{*}}$, and $\rho_{m p, i^{*}}$, and assume for them Normal priors with mean 0 and standard deviation 0.35 .

The posterior estimates regarding the robustness checks are reported in Table 2. Under the noninformative learning initialization, the estimated elasticity of substitution between domestic and foreign goods becomes larger. Non-fully rational beliefs and learning introduce more persistence in the system in this case: the estimates of habit formation and of the persistence in the terms of trade shock are reduced in this case. The situation is different when terms of trade data are not exploited in the estimation: the elasticity of substitution is lower, while the habit formation, the cost-push, and exchange rate disturbance persistence parameters generally increase. Given that the terms of trade disturbance is no longer present in the model, the volatility of the cost-push shock rises with respect to the baseline case to help the model fit the data despite the tighter restrictions. The notable changes in the estimates in the post-1997 sample are that the response to the exchange rate in the monetary policy rule is much closer to zero and the volatility of the cost-push is much lower. There is some evidence of an effect of foreign interest rates, although the magnitude of the response is small $\left(\rho^{*}=0.11\right)$. For the alternative habit specification, we estimate a degree of habit formation $h$ equal to 0.50 and a memory coefficient $\rho_{h}$ equal to 0.05 . The estimate suggests that, as in Fuhrer (2000), considering only a lagged term for consumption is not an unreasonable representation for habits. Finally, modeling shocks as correlated internationally does not significantly alter the findings: the estimated correlations fall between 0.2 , for demand shocks, to basically zero, for monetary policy innovations.

The table also reports the minimum and maximum shares of output variance due to the menu of global shocks over the samples for the different specifications. The minimum shares fall at the beginning of the sample with values around $0.20-0.30$, and the maximum values appear either 
around the financial crisis or in 2012, and attain values between 0.62 and 0.82 . Therefore, the overall conclusions do not substantially change under any of the previous alternatives.

Table 2: Posterior Estimates, Robustness Checks.

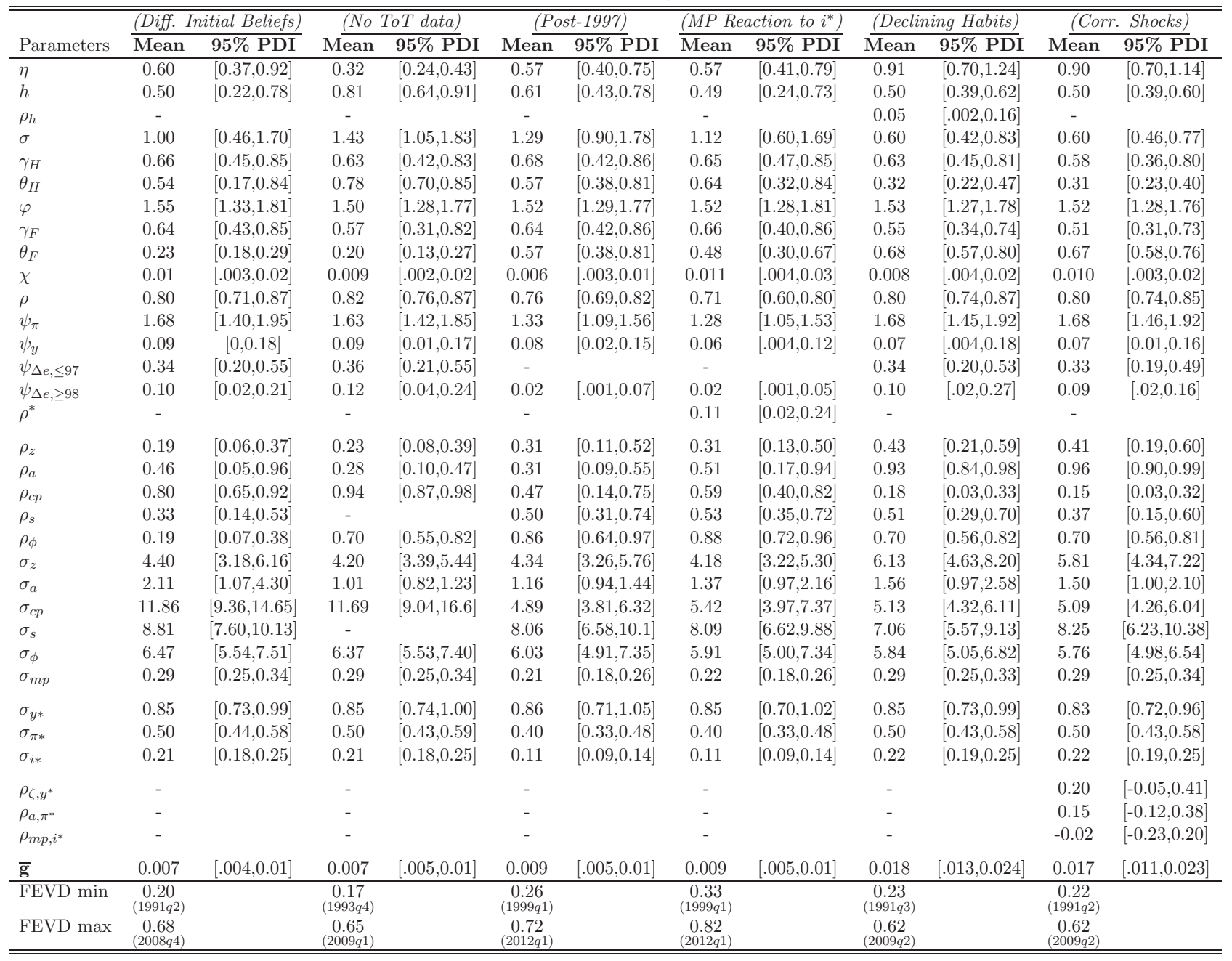

\section{Conclusions}

The recent macroeconomic literature has become interested in studying the impact that the steady process of globalization of the world economies over the past three decades may have had on macroeconomic dynamics in single countries. Various studies have argued that globalization may have made domestic variables, such as real output and inflation, potentially more responsive to global indicators than to local developments. A significant part of the research has focused on the U.S., including the papers testing the so-called 'global slack hypothesis' (e.g., Borio and Filardo (2007), Martinez-Garcia and Wynne (2012)). While some papers found significant effects, others 
conclude that globalization has not changed the behavior of the U.S. economy in a discernible way (i.e., Milani (2012)).

This paper has considered what we think is a better example to investigate the forces of globalization. We choose to focus on Korea, a developed small-open economy that is highly dependent on international trade with the rest of the world. Moreover, the importance of trade for the domestic economy (as exemplified by the trade to GDP share), has rapidly grown over the last two decades.

We have estimated a structural small open-economy, extended to include a number of nominal and real rigidities. To study the effects of globalization over the period, we have allowed the degree of openness of the economy to be time-varying in the estimation. Given the possible regime changes in the Korean economy before the 1990s, and the changes, possibly due to globalization, that may have affected Korea in the following decades, we have chosen to relax the extreme informational assumption required to agents under the rational expectations hypothesis. Instead, agents form near-rational expectations and try to learn over time the coefficients describing the relationships among macroeconomic (both domestic and global) variables.

Our results show that globalization has played an important role in the Korean economy. Domestic variables, such as output, inflation, and interest rates, which were prevalently driven by domestic factors in the early 1990s, have become much more sensitive to foreign and global developments. Now, roughly $70 \%$ of the variability of domestic variables can be attributed to external shocks. This result may open an interesting question for monetary-policymaking in a situation in which the domestic economy is driven, in large part, by factors that are outside its control.

Lastly, we would like to mention some caveats about our work. We have allowed here globalization to affect macroeconomic relationships at business cycle frequencies. But globalization may have had an impact even at lower frequencies, by changing the long-run growth rate of the Korean economy. ${ }^{7}$ We do not model that channel here, and leave to future research assessing its importance. Many empirical small open economy models abstract from capital to keep the system and estimation tractable, and we follow the same approach here. Adding capital and investment decisions may uncover new channels through which globalization affects the economy. Finally, with few exceptions, most models in the New-Open-Economy-Macro tradition do not include endogenous import-export decisions by firms. We share the same limitation here.

\section{References}

Ball, L. M. (2008), "Has Globalization Changed Inflation?" NBER Working Paper.

\footnotetext{
${ }^{7}$ Uy et al. (2013) show how international trade can explain the long-run structural change in the Korean economy.
} 
Beltran, D. O. and Draper, D. (2008), "Estimating the Parameters of a Small Open Economy DSGE Model: Identifiablity and Inferential Validity," FRB International Finance Discussion Papers.

Benigno, G., Benigno, P., and Ghironi, F. (2007), "Interest rate rules for fixed exchange rate regimes," Journal of Economic Dynamics and Control, 31, 2196-2211.

Bernanke, B. S. (2007), "Globalization and monetary policy," Fourth Economic Summit, Standford Institute for Economic Policy Research.

Borio, C. and Filardo, A. (2007), "Globalization and Inflation: New cross-country evidence of on the global determinants of domestic inflation," BIS Working Paper.

Evans, G. W. and Honkapohja, S. (2001), Learning and Expectations in Macroeconomics, Princeton University Press.

Fisher, R. W. (2006), “Coping with Globalization's Impact on Monetary Policy," Remarks for the National Association for Business Economics Panel Discussion at the 2006 Allied Social Science.

Fuhrer, J. C. (2000), "Habit Formation in Consumption and Its Implications for Monetary-Policy Models," American Economic Review, 90, 367-390.

Galí, J. and Monacelli, T. (2005), "Monetary policy and exchange rate volatility in a small open economy," Review of Economic Studies, 72.

Ihrig, J., Kamin, S. B., Lindner, D., and Marquez, J. (2010), "Some Simple Tests of the Globalization and Inflation Hypothesis," International Finance, 13, 343-375.

Justiniano, A. and Preston, B. (2010a), "Can structural small open-economy models account for the influnece of foreign disturbances?" Journal of International Economics, 81, 61-74.

Justiniano, A. and Preston, B. (2010b), "Monetary Policy and Uncertainty in an Empirical Small Open-Economy Model," Journal of Applied Econometrics, 25, 93-128.

Kam, T., Lees, K., and Liu, P. (2009), "Uncovering the Hit List for Small Inflation Targeters: A Bayesian Structural Analysis," Journalof Money, Credit and Banking, 41, 583-618.

Kang, K. Y. and Mook, S. B. (2009), "Impacts of Foreign Factos on Monetary Policy Effectiveness," BOK Monthly Bulletin. 
Kim, S. (2011), "Effects of U.S. Structural Shocks on Korean Economy," Review of International Money and Finance, 1.

Kim, Y. Y. and Park, J. Y. (2009), "Foreign Impulse Response Analysis for Korea in a Global Structural VAR Model," Kyong Je Hak Yon Gu, 57, 5-37.

Martinez-Garcia, E. and Wynne, M. A. (2012), "Global Slack as a Determinant of US Inflation," Federal Reserve Bank of Dallas. Globalization and Monetary Policy Institute Working paper No. 123.

Milani, F. (2007), "Expectations, Learning and Macroeconomic Persistence," Journal of Monetary Economics, 54, 2065-2082.

Milani, F. (2011), "Expectation Shocks and Learning as Drivers of the Business Cycle," Economic Journal, 121, 379-401.

Milani, F. (2012), "Has Globalization Transformed U.S. Macroeconomic Dynamics," Macroeconomic Dynamics, 16, 204-229.

Mishkin, F. S. (2009), "Globalization, Macroeconomic Performance, and Monetary Policy," Journal of Moeny, Credit and Banking, 41, 187-196.

Monacelli, T. (2005), "Monetary Policy in a Low Pass-Through Environment," Journal of Money, Credit, and Banking, 37, 1047-1066.

Rogoff, K. (2003), "Globalization and Global Disinflation," Paper prepared for the Federal Reserve Bank of Kansas City conference on "Monetary policy and Uncertainty: Adapting to a Changing Economy" Jackson Hole.

Romer, D. (1993), "Openness and Inflation: Theory and Evidence," Quarterly Journal of Economics, 108, 869-903.

Taylor, J. B. (2008), "The Impacts of Globalization on Monetary Policy," Banque de France Symposium on "Globalization, Inflation and Monetary Policy".

Uy, T., Yi, K.-M., and Zhang, J. (2013), "Structural Change in an Open Economy," Journal of Monetary Economics, 60, 667-682.

Woodford, M. (2007), "Globalization and monetary control," in Gali, J., Gertler, M.J. (Eds.), International Dimensions of Monetary Policy, University of Chicago Press. 